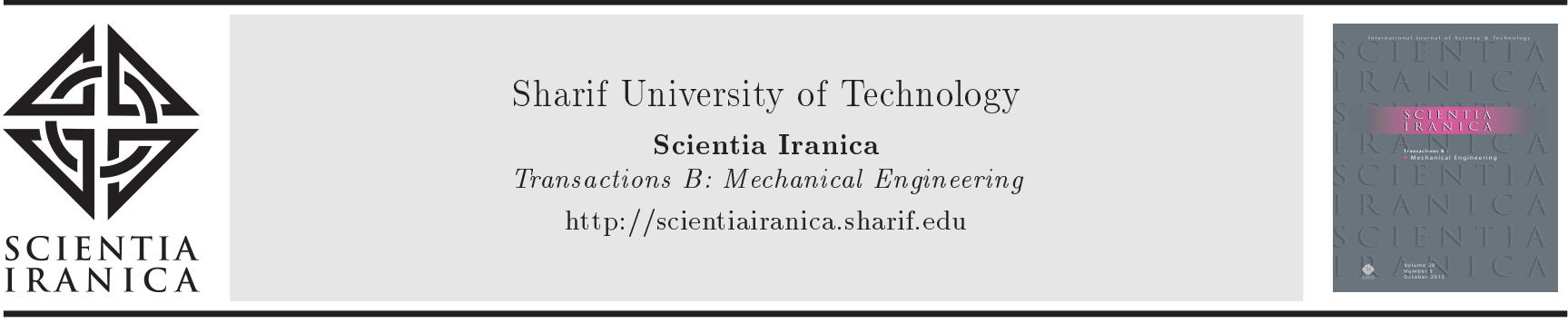

\title{
Lion pride optimization algorithm: A meta-heuristic method for global optimization problems
}

\author{
A. Kaveh ${ }^{a, *}$ and S. Mahjoubi ${ }^{b}$ \\ a. Centre of Excellence for Fundamental Studies in Structural Engineering, Iran University of Science and Technology, Narmak, \\ Tehran, P.O. Box 16846-13114, Iran. \\ b. School of Civil Engineering, Iran University of Science and Technology, Narmak, Tehran, P.O. Box 16846-13114, Iran.
}

Received 14 June 2017; received in revised form 6 August 2017; accepted 13 January 2018

\section{KEYWORDS}

Structural optimization;

Meta-heuristic

algorithm;

Lion pride

optimization

algorithm;

Global optimization;

Truss structures.

\begin{abstract}
This paper presents a new non-gradient nature-inspired method, Lion Pride Optimization Algorithm (LPOA), to solve optimal design problems. This method is inspired by the natural collective behavior of lions in their social groups "lion prides". Comparative studies are carried out using fifteen mathematical examples and two benchmark structural design problems in order to verify the effectiveness of the proposed technique. The LPOA algorithm is also compared with other algorithms for some mathematical and structural problems. The results have proven that the proposed algorithm provides desirable performance in terms of accuracy and convergence speed in all the considered problems.

(C) 2018 Sharif University of Technology. All rights reserved.
\end{abstract}

\section{Introduction}

Real-world structural optimization problems are highly complex and multimodal due to effects of design constraints. The main objectives of the designers can be categorized into four groups: minimum weight, minimum cost, goal performance and a combination of some desired purposes. Design variables (e.g., crosssectional areas and topology variables) are constrained by different accessible choices. Each decision has an impact on the structural responses such as internal forces, reaction forces, deflections, and natural frequencies, while no explicit relationship can easily be found.

Mathematical programming methods, such as Linear Programming (LP), combinatorial optimization, Quasi-Newton (QN), and nonlinear programming, can be applied to optimization problems. In this type

\footnotetext{
*. Corresponding author. Tel.: +982144249493;

Fax: +9821 ry240398

E-mail address: alikaveh@iust.ac.ir (A. Kaveh)
}

of optimization methods, the results highly depend on the quality of the starting points. Besides, the feasible search space of a real-world design problem is characterized by a number of nonlinear constraints and contains plenty of local optimums. These methods in complex problems may fall into the trap of local optima, and they are not suitable for these problems.

The global search meta-heuristic optimization techniques, as an alternative approach to the conventional mathematical methods, can escape from being trapped in local minima and attempt to obtain nearglobal optimum solutions. However, the latter methods use non-deterministic approaches in which finding the optimum solutions is not guaranteed. Each metaheuristic method has a unique behavioral base, and the performance of the algorithms is different in each problem space. For each algorithm, elevated performance over one class of problems comes with weak performance over other classes, and it is impossible for one metaheuristic algorithm to derive optimal solutions in all classes of problems. Thus, searching for new meta-heuristic optimization algorithms is an open problem [1]. 
Nowadays, designers face new problems every day, and the complexity of the design optimization problems increases by recent advances in structural technologies. In order to tackle complex issues arising from the design problems, the necessity of proposing robust and new algorithms is evident.

The meta-heuristic methods consist of one or several search agents that explore the feasible region. The movements of each search agent are guided by a combination of randomness and one or more predefined rules. The behavior of search agents mainly has a natural inspiration. In the last decade, many new nature-based stochastic optimization methods have been developed, each of which mimics different sources of inspiration from nature; for instance, vibrating particle systems algorithm [2]; water evaporation optimization [3]; social spider algorithm [4]; dragonfly algorithm [5]; grey wolf optimizer [6]; charged system search [7]; and firefly algorithm [8]. However, inspiration has no border (e.g., artificial inspired mine blast [9] that mimics the explosion of mine bombs; and harmony search [10] that is inspired by the process of searching for better harmony [10]. A collection of 17 recently developed metaheuristics can be found in [11].

There are three different optimization algorithms in the literature, inspired by various aspects of a lion's life. Rajakumar [12] proposed the lion's algorithm based on the interaction between nomad and resident lions and the fight between resident lions and newly mature lions. Likewise, Lion Pride Optimizer (LPO) proposed by Wang et al. [13] and inspired by lions' life was developed. Yazdani and Jolai [14] proposed Lion Optimization Algorithm (LOA) that is based on the behavior of nomad and resident lions. Cooperative hunting of female lions in the pride, mating in pride, male lions defending against new mature resident males, mature lions defending against nomad males, and migratory behavior of female lions have been simulated in the mathematical concept of the algorithm [15].

This article proposes a new algorithm called Lion Pride Optimization Algorithm (LPOA) as an alternative approach to solving design optimization problems. As the name implies, the LPOA algorithm mimics some behaviors of lions in social groups called pride. A lion pride consists of lionesses, offspring, and a small number of male lions, each member having specific duties. Female lions have cooperative strategies for hunting. Male lions protect their territory against invading lions or other predators; for this reason, they usually move within their dominated areas.

In this paper, first, the main inspiration of the LPOA algorithm is presented. Then, the mathematical concept of the algorithm is introduced comprehensively. The relative efficiency of the proposed algorithm is next evaluated by solving some mathematical problems and compared to five modern meta-heuristic algorithms. Finally, two well-studied structural design problems are solved by the proposed method to demonstrate its effectiveness.

\section{Inspiration from nature: background}

\subsection{Social groups}

The lion (Panthera leo) is one of the largest and most powerful members of the Felidae family. Unlike other felids, they have a social innate behavior. Lions have two types of social behavior:

1. Residents that are members of social groups-called pride;

2. Nomads scattered in their habitats.

These categories are not mutually exclusive; a nomad may become a resident, and vice versa; however, there is a dichotomy between the two types of life [15].

All the members are engaged in a wide variety of group-leveling activities, including group hunting, communal club rearing, and group territoriality [15]; however, gender roles are almost specific. Each pride consists of 2 to 4 adult males, several adult females, and a number of sub adults and cubs [15]. It has been found that the average group size is 4 to 5 with a maximum of 15 [16].

\subsection{Hunting}

All the members typically hunt together as a team, and each member has a persistent division of labors during cooperative hunting. The hunting group generally involves a formation, whereby some lionesses (wings) circle prey, while others (centers) wait for prey to move towards them [17]. It should be stated that hunting groups are more cooperative when tackling difficult preys, such as elephants and buffalos.

The observations of hunting group provide evidence that not all lions present in the group participate in the activity; some in a larger group sizes may 'cheat' (exploit the foraging activities of conspecifics) during cooperative hunts [17]. An individual cheats only if it spots the prey first and stops hunting if a companion starts to hunt [18]. Therefore, individuals that do not participate in group hunts withhold effort that would increase the group's success rate [17].

\subsection{Excursion}

The territorial excursions of male lions provide effective protection for the whole pride territory. Lions leave scent marks within and on the borders of their territories in order to inform potential intruders, whose area is already occupied [19], and nomadic lions can warn by a sniff how recently a territorial male has passed on patrol and, thus, how safe it would be to stroll through the territory [20]. It can be mentioned that 
there is a considerable amount of overlap between pride areas [15].

\subsection{Mating}

Lions have no particular breeding season. They mate at any time of the year and, also, when females do not rear cubs. A lioness may mate with multiple partners when she is in heat [21].

\subsection{Intragroup interaction}

Male lions do not behave compassionately towards the offspring, even towards their own offspring [22]. Males compete for the exclusive access to a pride and father, typically; only a single cohort of young females can negotiate long-term territorial boundaries and breed repeatedly over their lifetime [23]. Accordingly, mature resident males oust young mature male lions from their birth pride. A newly-matured lion is a new rival and must be eliminated. Mature lions fight each other, and weaker ones must leave their natal prides.

\subsection{Migration}

Some sub-adult lionesses leave the pride to become nomadic [15], and some of them migrate to other prides. Most of them remain with their natal pride, and just surplus lionesses are forced to leave their own group.

\section{Lion Pride Optimization Algorithm (LPOA)}

The LPOA is a population-based meta-heuristic algorithm that mimics some parts of the lion's life, and each agent is considered as a lion. In this technique, the search process is far dissimilar to all of the conventional optimization algorithms, such as Particle Swarm Optimization (PSO), Genetic Algorithm (GA), Cuckoo Search (CS), Simulated Annealing (SA), Harmony Search (HS), and Tabu Search (TS). In the proposed method, there are two different types of search agents with distinct types of defined rules. Moreover, they are divided into sub-groups, namely prides. In addition, each sub-group, which consists of females and males, probes into the search space unity. Each sub-group explores the defined space independently; therefore, the cumulative knowledge acquired by each pride's member is different from that by other groups' members. The migration mechanism engendering these distinctions reduces progressively. This part of the method urges the agents to probe into the search space better in the early stages of the optimization process and, then, to make them find near-global optimal solutions. Additionally, this mechanism can reduce the probability of being trapped due to transferring information between prides.

The mathematical model of the proposed algorithm is provided in the following.

\subsection{The formation of pride groups}

The lions and lionesses are the search agents of the proposed algorithm, and each agent explores the defined search space systematically.

The first step is to initialize the first population of the lions and form pride groups randomly:

$$
\begin{aligned}
& a_{\min , i}<a_{i}<a_{\max , i} \quad i=1,2, \cdots, n v, \\
& \text { lion }_{j}=\left[a_{1, j}, \cdots, a_{n, j}\right] \quad j=1,2, \cdots, n l, \\
& \text { Pride }_{k}=\left(\begin{array}{c}
\operatorname{lion}_{1, k} \\
\vdots \\
\text { lion }_{n r, k}
\end{array}\right)=\left(\begin{array}{ccc}
a_{1,1, k} & \cdots & a_{1, n v, k} \\
\vdots & \ddots & \vdots \\
a_{n r, 1, k} & \cdots & a_{n r, n v, k}
\end{array}\right) \\
& k=1,2, \cdots, n p,
\end{aligned}
$$

where lion $_{j}$ determines the initial position of the $j$ th agent; $a_{\min , j}$ and $a_{\max , j}$ represent the minimum and maximum permissible values for the $i$ th variable; $a_{j}$ indicates a random value between $a_{\min , j}$ and $a_{\max , j}$; $n v$ is the number of design variables; $n l$ is the number of total population; pride ${ }_{k}$ includes the resident lions' position in pride $k ; n r$ is the population of residents; $n p$ represents the number of prides.

Fitness value of each lion is computed by evaluating the objective function as follows:

$$
\begin{aligned}
\text { fit }_{j} & =\text { objun }_{\left(\text {lion }_{j}=\left[a_{1, j}, \cdots, a_{n, j}\right]\right.} \\
j & =1,2, \cdots, n l,
\end{aligned}
$$

where objun is the objective function, and $f i t_{j}$ is the fitness of the $j$ th agent.

\subsection{Main loop}

Mathematical modeling of the LPOA with some characteristics of lions' life is presented in this subsection. Some variables that change in each iteration are described below:

$$
\begin{array}{ll}
D_{i}=D F \times a m p_{i} & i=1,2, \cdots, n v, \\
a m p_{i}=a_{\max , i}-a_{\min , i} & i=1,2, \cdots, n v,
\end{array}
$$

where $D$ represents diversification matrix; $D F$ is the diversification factor that is constant in each iteration; however, it can be changed during the process of optimization. By examining different changes of this factor, it should decrease during the process in order to find near-global solutions. Figure 1 shows different types of changes of the diversification factor versus the number of iterations. Furthermore, the diversification factor can be changed adaptively according to the obtained fitness values or exploration success rate. In this study, the diversification factor declines rectilinearly with respect to the increasing number of iterations in the optimization procedure. 


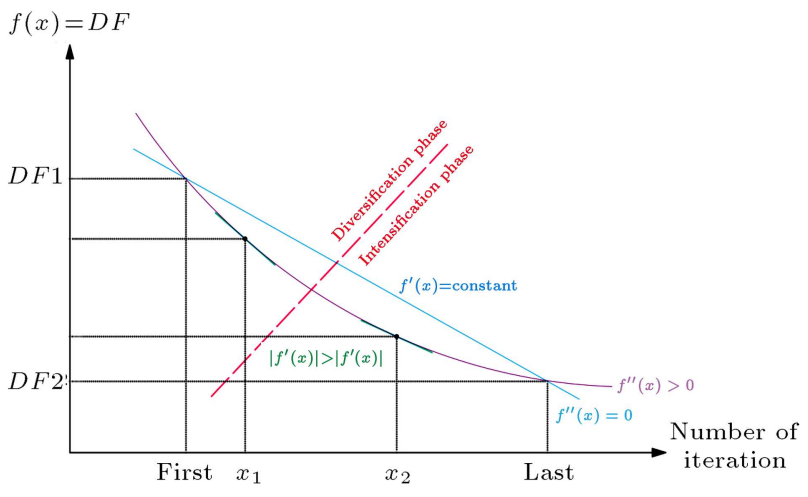

Figure 1. Diversification factor change diagram.

\subsubsection{Hunting}

The formulation of the cooperative hunting of lionesses is described as follows: All female lions in each pride are sorted as their fitness; after that, they are grouped into three groups. The best female lions' group members are named as "chasers". The second best group" members are labeled as "wingers", and the third group is called as "cheaters". Figure 2 shows the process of dividing female lions into these three general groups. Afterwards, the hunting subgroups are formed by three members, each of which is selected unmethodically from different general groups. In other words, each general group has a member in hunting subgroups. After the formation of three-member hunting groups, each group follows different prey to catch. The prey of each subgroup is selected randomly from the best position of all pride members.

Now, the position of each chaser changes using Eq. (7):

$$
\begin{aligned}
\text { Chaser }_{\text {new }}= & \text { Chaser }+H_{1} \times \text { rand }+(D) \\
& \times(2 \text { rand }-1),
\end{aligned}
$$

$$
H_{1}=(\text { Prey }- \text { Chaser }),
$$

where Chaser new and Chaser are the new and existing positions of each chaser lion, respectively; rand represents a random number between zero and one; and Prey indicates the position of the prey.

The new position of wing hunters in each iteration follows the equation mentioned below:

$$
\begin{aligned}
\text { Winger }_{\text {new }}= & \text { Prey }+H_{2} \times|W| \times \text { rand }+(D) \\
& \times(2 \text { rand }-1),
\end{aligned}
$$

where Winger $_{i, n e w}$ indicates the new position of Winger hunter lion, and $H_{2}$ is a random unit vector perpendicular to vector $W$ considered as follows:

$$
\begin{aligned}
& W=\text { Prey }- \text { Winger }, \\
& |W|=\sqrt{W_{1}^{2}+\cdots+W_{n}^{2}} .
\end{aligned}
$$

Finally, Eq. (12) defines the movements of the cheater:

$$
\begin{aligned}
& \text { Cheater }_{\text {new }}= \text { Prey }+H_{3} \times \text { rand }+(D) \\
& \times(2 \text { rand }-1), \\
& H_{3}=(\text { Prey }- \text { Cheater }),
\end{aligned}
$$

where Cheater new represents the new position of the Winger hunter lion, and Cheater is the present position of the Winger hunter lion.

The schematic diagram of movements of each hunter is depicted in Figure 3.

\subsubsection{Excursion}

The simulation of male lions' excursion is formulated by the following equation:

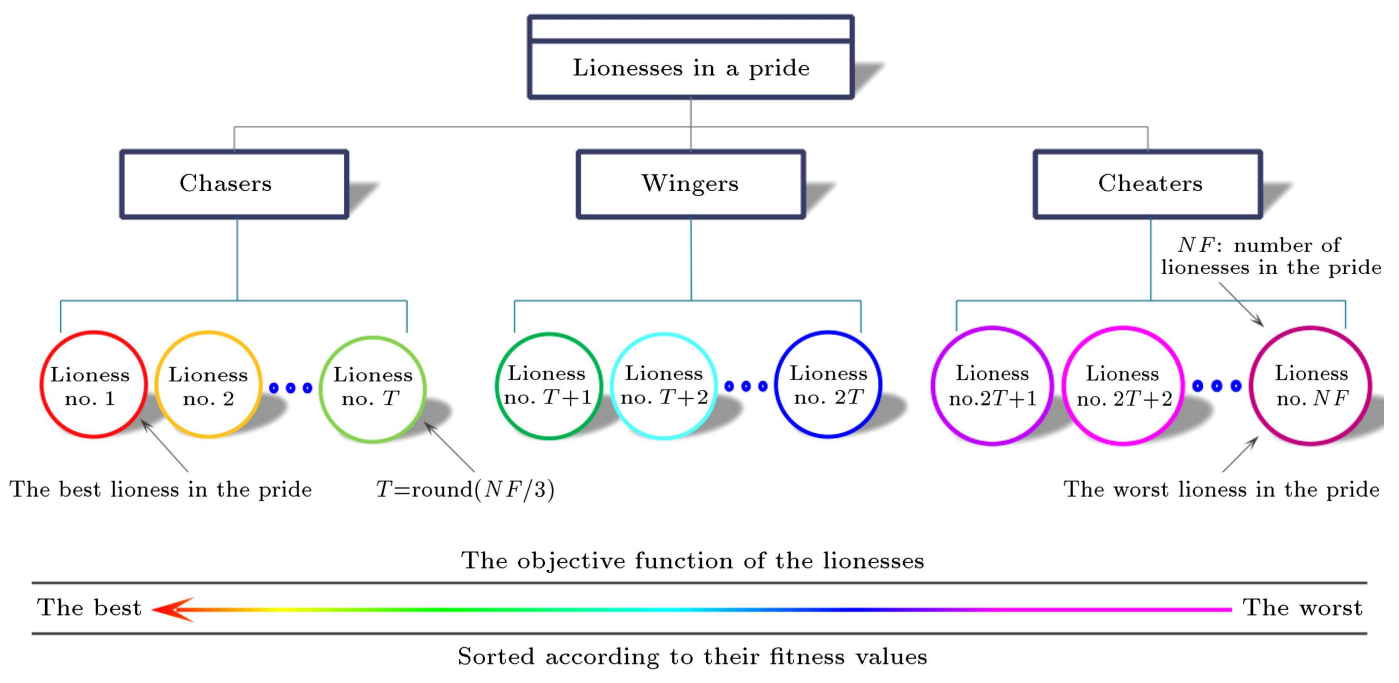

Figure 2. The formation of general hunting groups in a pride with twelve lionesses. 


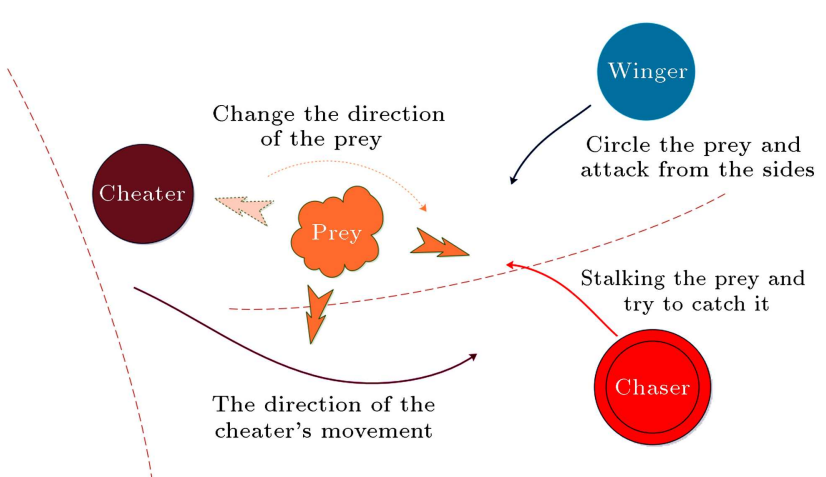

Figure 3. The schematic strategy of lionesses to catch the prey.

$$
\text { Male } \text { Lion }_{n e w}=\text { Territory }+E \times(D) \times(2 \text { rand }-1) \text {, }
$$

where Male Lion new indicates the new position of the male lion, and Territory is formulated as follows:

$$
\text { Territory }_{i}=\text { Best Positions }(\text { rand } \times T R)_{i},
$$

Best Positions $=$ sort $[$ Male best Positions;

$$
\text { Female best Positions]. }
$$

Best Positions represent the collective understanding of the pride's members about the search space. The cumulative best positions of the resident lions (including both males and females) are sorted from the best to the worst according to the corresponding fitness; $E$ is an excursion constant; $T R$ indicates the territory ratio. In accordance with Eq. (15), just rand $\times T R$ percent of the best memories are saved in Territory.

\subsubsection{Mating}

$M$ percent of the lionesses (mating probability) in each pride mate with single or multiple resident lions. The lion(s) is/are selected randomly from the same pride as the selected female.

Two offspring breed in each mating according to the following equations:

$$
\begin{aligned}
& \text { Offspring }_{1}=\beta \times \text { Female Lion }+\sum_{l=1}^{n m} \frac{1-\beta}{\sum_{l=1}^{n m} S_{l}} \\
& \times \text { Male Lion } \times \text { } \times S_{l} \text {, } \\
& \text { Offspring }_{2}=(1-\beta) \times \text { Female Lion }+\sum_{l=1}^{n m} \frac{\beta}{\sum_{l=1}^{n m} S_{l}} \\
& \times \text { Male Lion } \times S_{l},
\end{aligned}
$$

where Female Lion indicates the best position of the selected lioness; Male Lion $_{l}$ represents the best position of the $l$ th lion in the pride; $S_{l}$ equals 1 if male $l$ is in the coalition; otherwise, it equals $0 ; \mathrm{nm}$ is the number of resident males in the pride; $\beta$ is a randomly generated number with a normal distribution, mean value of 0.5 , and standard deviation of 0.1 . It is assumed that the chance of giving birth to a female or a male lion is $50: 50$.

\subsubsection{Intragroup interaction}

This behavior is simulated according to the following rule: The number of male lions in each pride is always in equilibrium; in each iteration, weaker males (according to their fitness values) must leave the pride.

\subsubsection{Migration}

The simulation of the natural phenomenon of the migration of resident lionesses is formulated as follows: The lionesses in each pride migrate with the probability of immigration rate (I) in every iteration. Further, the number of females in each pride is always constant. As a result, surplus female lions in each pride get out of the pride and become nomad. In this mechanism, the knowledge of the migratory lioness (the existing position and the best position of the agent so far) is transferred into the new pride.

Finally, the pseudo codes of the LPOA are defined in Figure 4, and a flowchart of the proposed algorithm is illustrated in Figure 5.

\section{Performance evaluation in mathematical problems}

It is common in optimization frameworks to evaluate the performance of the new algorithms in comparison with other algorithms on a set of mathematical functions. All 15 functions of benchmark problems based on artificially-created functions, such as the CEC 2015 [24], are considered to compare the presented algorithm with the known robust algorithms in structural problems.

Test functions are considered with different characteristics to test the performance of the LPOA algorithm from different points of view. These comparative functions can be divided into four types with respect to their definitions. Unimodal functions have single optimum and measure the exploitation and convergence of an algorithm. In hybrid functions, the variables are randomly divided into some subsets; then, different basic functions are used for different subsets [24]. For comparing the local optima relief in addition to other features, multimodal functions are defined with multiple optimum positions. The composite functions are mostly the combined, rotated, shifted, and biased versions of unimodal and multi-modal test functions.

The idea is to compose the standard benchmark functions to construct a more challenging function with a randomly located global optimum and several randomly located deep local optima [25]. The global optimum position shift in each type of functions according to the shift data is presented in Problem Definitions 


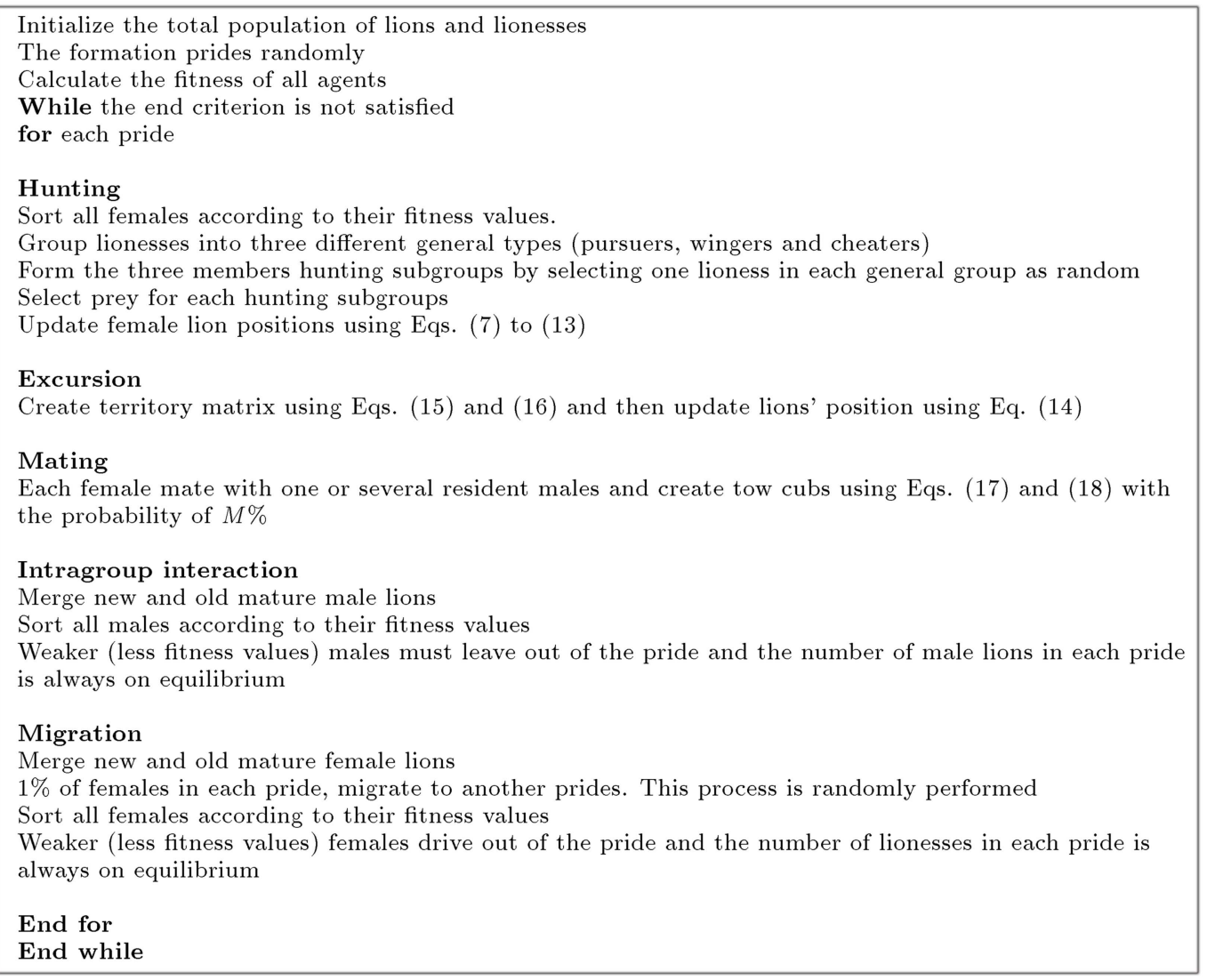

Figure 4. Pseudocode of the LPOA.

Table 1. Description of unimodal benchmark functions.

\begin{tabular}{|c|c|c|c|}
\hline \multicolumn{4}{|c|}{ Category } \\
\hline & Function name & Function & $F_{i}^{*}$ \\
\hline F1 & Rotated high conditioned elliptic function & $F_{1}(x)=f_{1}\left(M\left(x-o_{1}\right)\right)+F_{1}^{*}$ & 100 \\
\hline $\mathrm{F} 2$ & Rotated cigar function & $F_{2}(x)=f_{2}\left(M\left(x-o_{2}\right)\right)+F_{2}^{*}$ & 200 \\
\hline
\end{tabular}

Table 2. Description of multimodal benchmark functions.

\begin{tabular}{|c|c|c|c|}
\hline \multicolumn{2}{|r|}{ Function name } & Function & $F_{i}^{*}$ \\
\hline F3 & Shifted and rotated Ackley's function & $F_{2}(x)=f_{5}\left(M\left(x-o_{2}\right)\right)+F_{2}^{*}$ & 300 \\
\hline F4 & Shifted and rotated Rastrigin's function & $F_{4}(x)=f_{8}\left(M\left(\frac{5.12\left(x-o_{4}\right)}{100}\right)\right)+F_{4}^{*}$ & 400 \\
\hline F5 & Shifted and rotated Schwefel's function & $F_{5}(x)=f_{9}\left(M\left(\frac{1000\left(x-o_{5}\right)}{100}\right)\right)+F_{5}^{*}$ & 500 \\
\hline
\end{tabular}

and Evaluation Criteria for the CEC 2015 Competition on Learning-based Real-Parameter Single-Objective Optimization [24]. Mathematical test functions that are considered in this article are given in Tables 14. Different basic functions are used to construct the mentioned benchmark problems. These functions are depicted in Table 5. Furthermore, Figure 6 shows the perspective view of the fitness functions for the test cases considered in this section.
In this section, five modern optimization methods are compared to the LPOA consisting of Particle Swarm Optimization (PSO) algorithm accredited to Kennedy and Eberhart [26], colliding bodies optimization developed by Kaveh and Mahdavi [27], Enhanced Colliding Bodies Optimization (ECBO) algorithm proposed by Kaveh and Ilchi Ghazaan [28], water cycle algorithm proposed by Eskandar et al. [29], the Lion Optimization Algorithm (LOA) proposed 


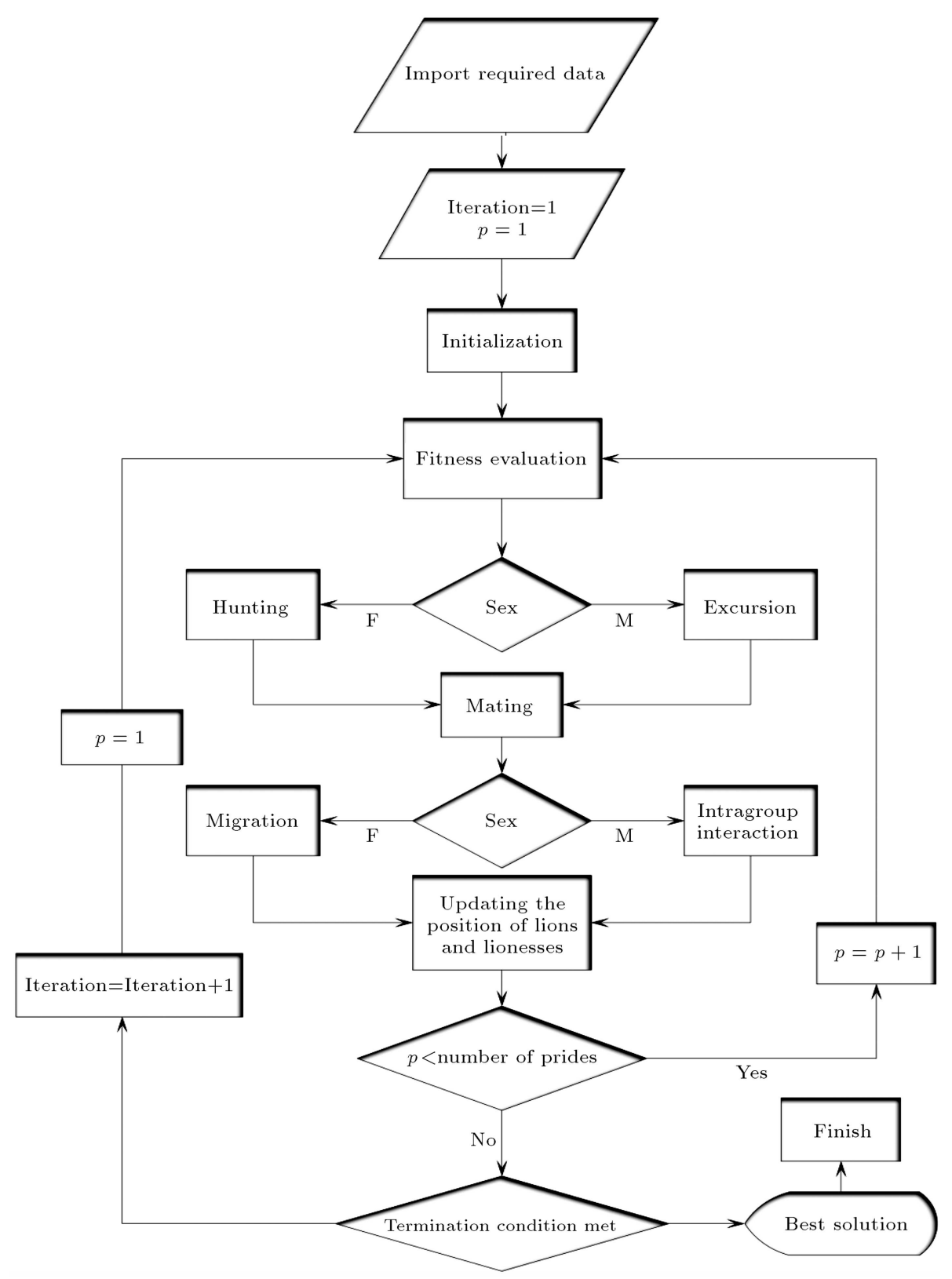

Figure 5. Simplified flowchart of the LPOA.

by Yazdani and Jolani [14], and The Whale Optimization Algorithm proposed (WOA) by Mirjalili and Lewis [30].

The same search ranges are defined for all test functions as $[-100,100]^{D}$. In addition, all optimization parameters in each algorithm employed are assumed as recommended in the related articles. In all cases, the population size is set to 30 , and 10-dimensional functions are used in this research. In addition, the maximum Number of Function Evaluations (NFE) in each function is set to 30000 . Furthermore, 50 separate runs are carried out for each algorithm similar to the setting of the CEC 2015 single-objective optimization competition.

\subsection{Adjusting LPOA parameters}

Sensitivity analysis is performed in this section to evaluate how the parameters of the LPOA influence the results. Five related parameters in the proposed algorithm are analyzed in different mathematical functions to find a proper set of parameters due to the scatter plots of each parameter versus the fitness values and, eventually, have proper behavior in the process of optimization. In addition, the samples are taken from the marginal distribution of each factor.

Four mathematical test problems of F1, F3, F6, and $\mathrm{F} 9$ are used to tune the parameters of the proposed algorithm. These functions are representative of different types of the considered mathematical functions. 
Table 3. Description of hybrid benchmark functions.

\begin{tabular}{|c|c|c|c|}
\hline \multicolumn{4}{|c|}{ General definitions } \\
\hline \multicolumn{4}{|c|}{$F(x)=g_{1}\left(M_{1} z_{1}\right)+g_{2}\left(M_{2} z_{2}\right)+\cdots+g_{N}\left(M_{N} z_{N}\right)+F^{*}(x), z=\left[z_{1}, z_{2}, \cdots, z_{N}\right]$} \\
\hline \multicolumn{4}{|c|}{$z_{1}=\left[y_{s_{1}}, y_{s_{2}}, \cdots, y_{s_{n_{1}}}\right]$} \\
\hline \multicolumn{4}{|c|}{$z_{2}=\left[y_{s_{n_{1}+1}}, y_{s_{n_{1}+2}}, \cdots, y_{s_{n_{1}+n_{2}}}\right], \cdots, z_{N}=\left[\begin{array}{l}y_{s_{N-1}}, y_{s_{N-1}-1} \sum_{k=1} n_{i}+2 \\
\sum_{i=1}\end{array}, \cdots, y_{s_{D}}\right]}$, \\
\hline \multicolumn{4}{|c|}{$y=x-o_{i}, S=\operatorname{randperm}(1, D)$} \\
\hline \multicolumn{4}{|c|}{$n_{i}:$ dimension for each basic function, $\sum_{i=1}^{N} n_{i}=D$} \\
\hline \multicolumn{4}{|c|}{$n_{1}=\left[p_{1} D\right], n_{2}=\left[p_{2} D\right], \cdots, n_{N-1}=\left[p_{N-1} D\right], n_{N-1}=\left[p_{N-1} D\right], n_{N}=D-\sum_{i=1}^{N-1} n_{i}$} \\
\hline \multicolumn{4}{|c|}{$p:$ used to control the percentage of $g_{i}(x)$} \\
\hline & unction name & Function & $F_{i}^{*}$ \\
\hline & $\begin{array}{l}\text { Hybrid Function } 1 \\
\qquad(N=3)\end{array}$ & $g=\left\{f_{9}, f_{8}, f_{1}\right\}, p=[0.3,0.3,0.4]$ & 600 \\
\hline F7 & $\begin{array}{l}\text { Hybrid Function } 2 \\
\qquad(N=4)\end{array}$ & $g=\left\{f_{7}, f_{6}, f_{4}, f_{14}\right\}, p=[0.2,0.2,0.3,0.3]$ & 700 \\
\hline F8 & $\begin{array}{l}\text { Hybrid Function } 3 \\
\qquad(N=5)\end{array}$ & $g=\left\{f_{14}, f_{12}, f_{4}, f_{9}, f_{1}\right\}, p=[0.1,0.2,0.2,0.2,0.1]$ & 800 \\
\hline
\end{tabular}

The selected set of parameter values of LPOA is depicted in Table 6 .

\subsection{Numerical results and statistical test}

The comparative results given from the mentioned algorithm are tabulated in Tables 7 and 8 . Table 7 shows information about the minimum, maximum, and standard deviations of the corresponding objective function test, and the values of Table 8 indicate the average error rate derived from the considered algorithms. The average error rate datasets can be considered as a means for measuring the performance of optimization techniques. The results imply that the LPOA is able to generate competitive answers to its counterparts. It can be noted that the proposed optimization technique finds the best answers in 13 out of 15 function problems.

The comparative convergence curve of some objective function is illustrated in Figure 7 . The convergence curves show that the LPOA works well; in most cases, the LPOA has higher efficiency than other considered algorithms do, for the benchmark functions.

For the validation of significance of results, it is assumed that all algorithms are performed on the null hypothesis, and all algorithms are similar when solving these unconstrained functions. Friedman rank test $[31,32]$ and different post-hoc analyses were employed together to show the difference between algorithms in a statistically significant way. Suppose that a level of significance $\alpha=0.05$ was selected, and the hypothesis would be rejected only if the value of $p$ yielded by the test was not greater than the value of 0.05 .

Table 9 depicts the ranks computed through the Friedman test, and the LPOA is the best performing algorithm in the study. In addition, $p$ value obtained by the test is 0.00 . Consequently, the Friedman test strongly suggests the existence of significant differences among the considered algorithms with a significance level of 0.05, as assumed.

The Friedman test only can detect significant differences over the whole multiple comparisons, being unable to establish proper comparisons between some of the algorithms considered [33]. For this reason, Holm [34], Rom [35], Hommel [36], Finner [37], Holland and Copenhaver [38] and $\mathrm{Li}$ [39] post-hoc procedures are performed in order to find the concrete pairwise comparisons, which produce differences. 
Table 4. Description of composition benchmark functions.

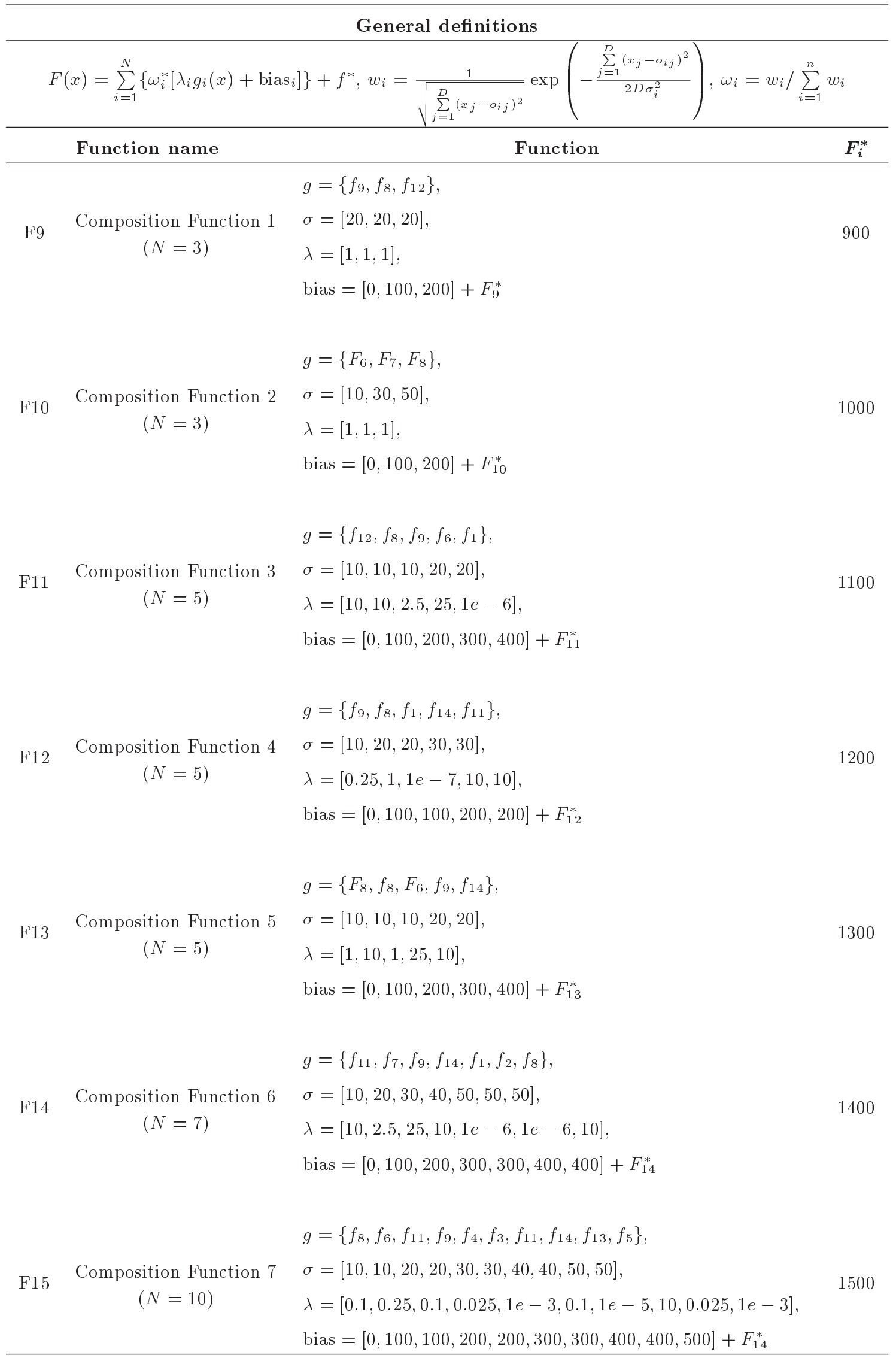


Table 5. Description of the basic functions.

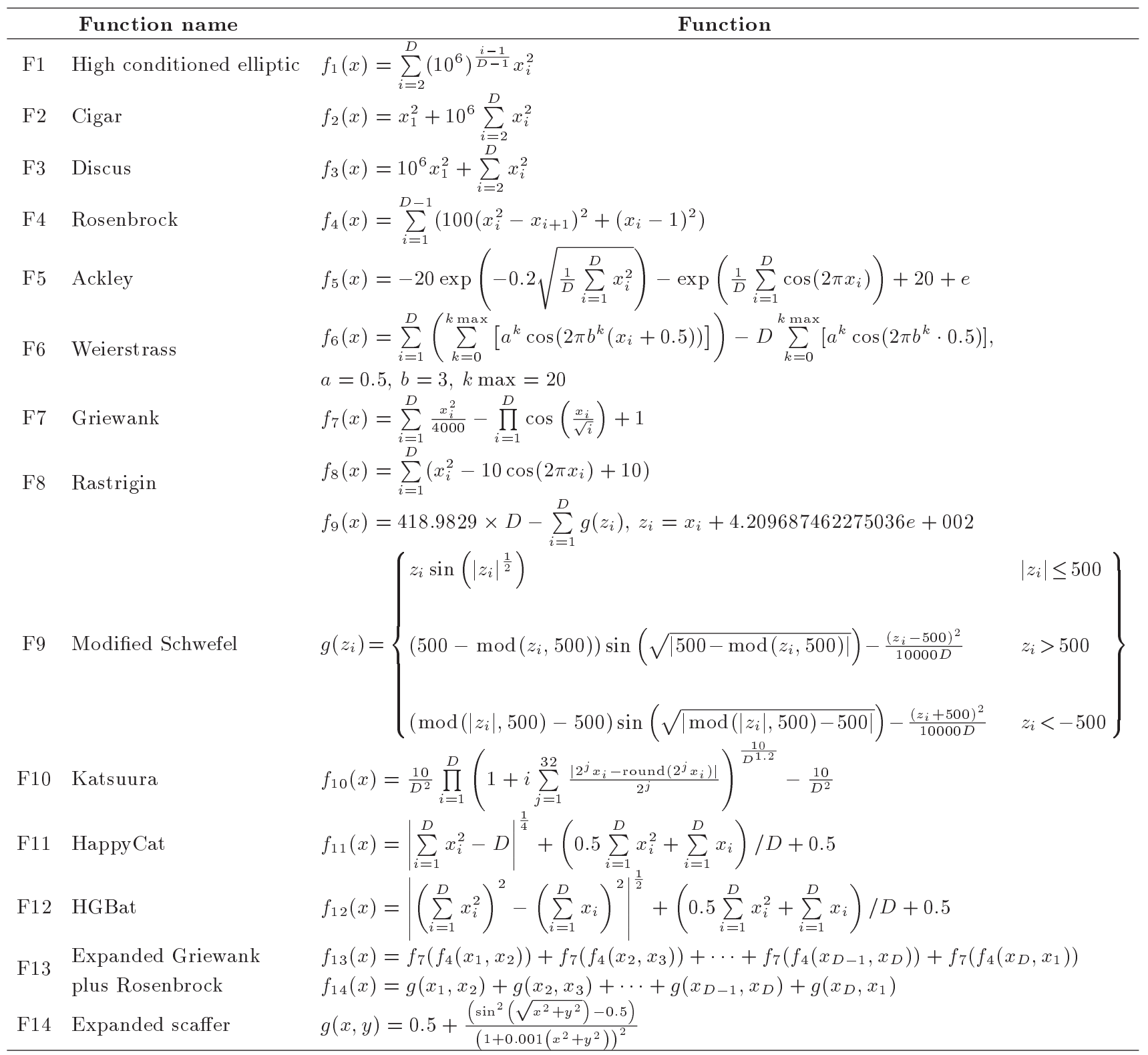

Table 6. Parameter values of LPOA in mathematical functions.

\begin{tabular}{lc}
\hline \multicolumn{1}{c}{ Parameter } & Value \\
\hline Number of prides & 5 \\
Lions in each pride & 6 \\
Male lions in each pride & 2 \\
Female lions in each pride & 4 \\
Territory ratio & 0.4 \\
Mating probability & 0.6 \\
Immigration rate & 0.6 \\
diversification factor & 10e-03 to 0 \\
\hline
\end{tabular}

Table 10 shows $p$ values obtained through the application of the considered post-hoc methods. Adjusted $p$ values can be compared directly with the chosen significance level. It can be seen that the null hypothesis is rejected subsequently as all output values are smaller than $\alpha=0.05$, and the results of LPOA are significantly better than other techniques statistically.

\section{Performance evaluation in constrained design problems}

Design optimization problems are often constrained and complex with a lot of local optima and frequently limited by different constraints as material properties, feasible strength, displacements, load cases, and type or size of members. Thus, in order to demonstrate the efficiency of the proposed methodology, three wellstudied design engineering benchmark problems are 


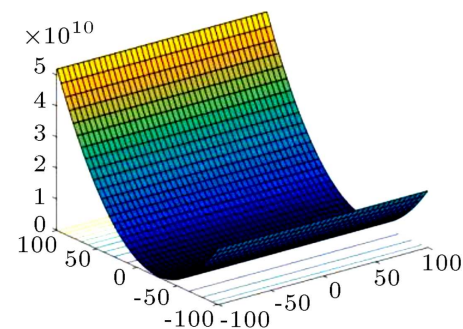

$\mathrm{F} 1$

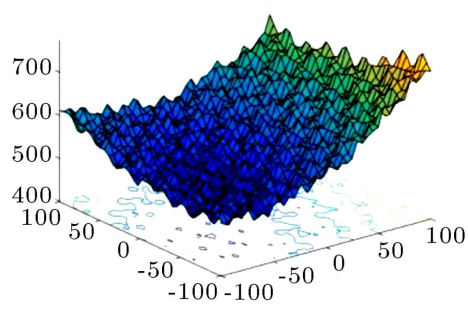

F4

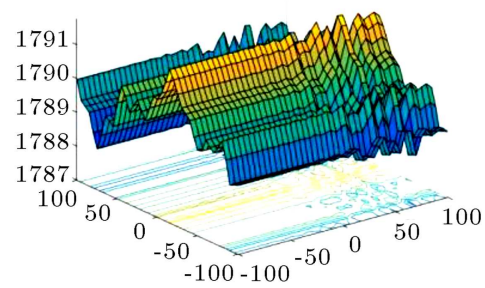

F 7

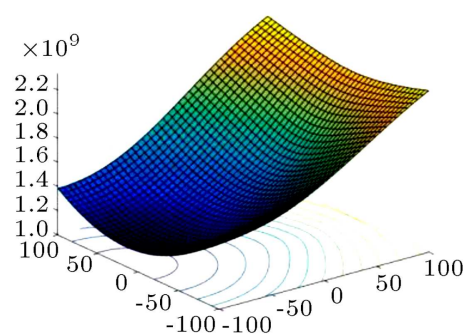

F10

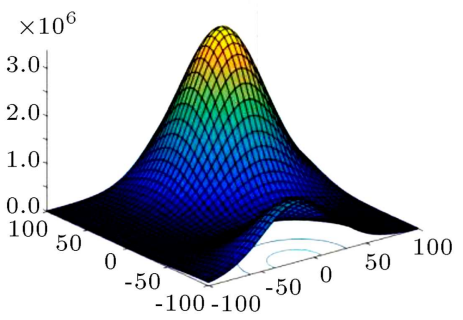

F13

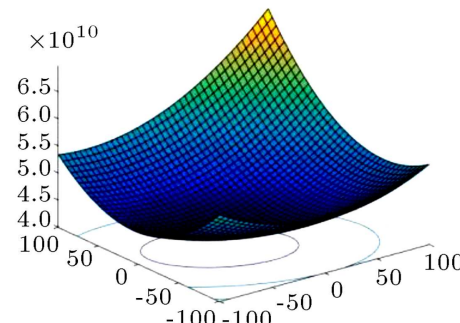

F2

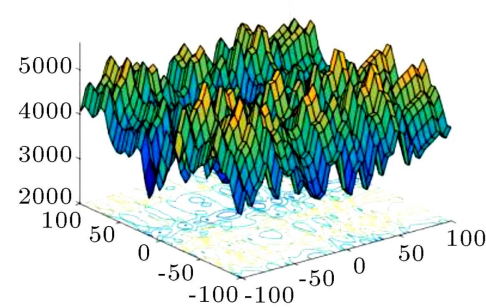

F5

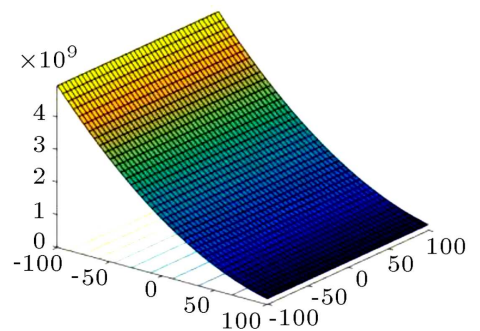

F8

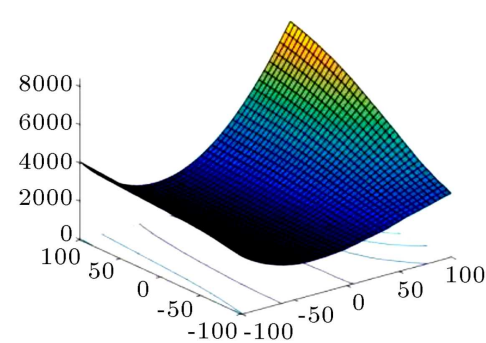

F11

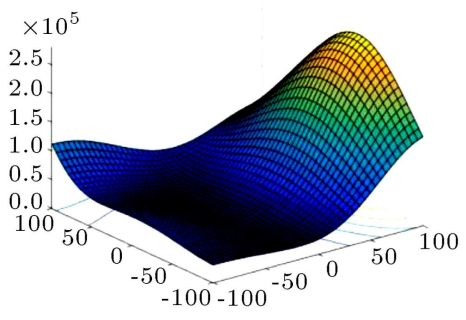

F14

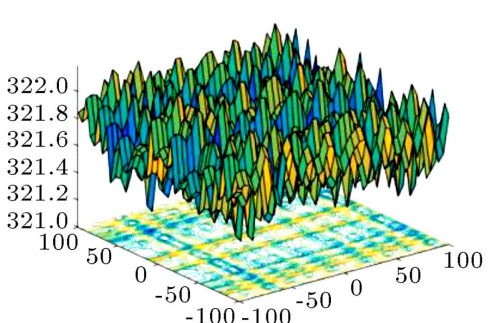

F3

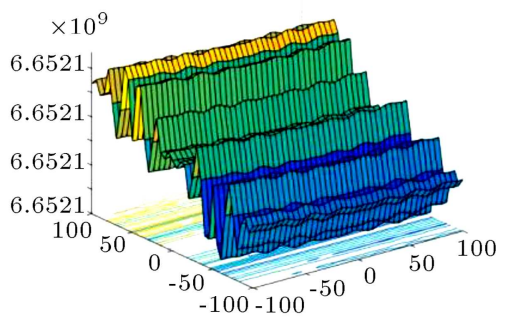

F6

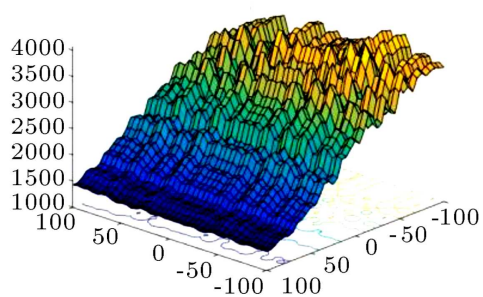

F9

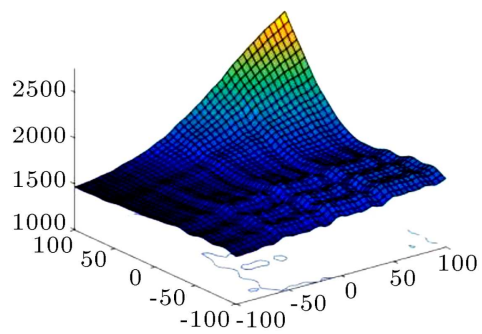

F12

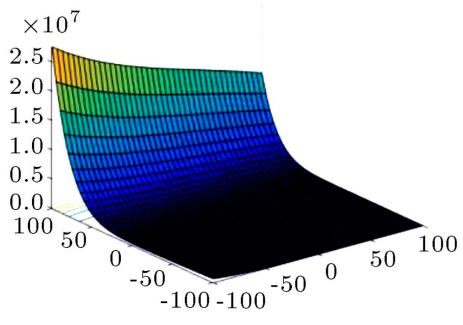

F15

Figure 6. 2D Search space representations of benchmark mathematical functions.

solved with LPOA. In addition, the solutions are compared with different state-of-the-art approaches.

The LPOA algorithm is coded in MATLAB, and structural analysis is performed with the direct stiffness method.
The penalty approach is used for constraint handling. The penalty function method has been the most popular constraint-handling technique due to its simple principle and ease of implementation [40]. If the constraints are not violated, the penalty will be 
Table 7. Comparative results on mathematical test functions.

\begin{tabular}{|c|c|c|c|c|c|c|c|c|}
\hline \multirow{2}{*}{ Function } & & \multicolumn{7}{|c|}{ Algorithm } \\
\hline & & Present work & PSO & CBO & ECBO & WCA & LOA & WOA \\
\hline \multirow{3}{*}{ F1 } & Min. & $4.67 \mathrm{E}+03$ & $5.20 \mathrm{E}+03$ & $8.14 \mathrm{E}+04$ & $3.18 \mathrm{E}+04$ & $2.47 \mathrm{E}+03$ & $3.31 \mathrm{E}+05$ & $9.99 \mathrm{E}+05$ \\
\hline & Max. & $3.18 \mathrm{E}+05$ & $1.60 \mathrm{E}+06$ & $3.41 \mathrm{E}+06$ & $6.65 \mathrm{E}+06$ & $2.91 \mathrm{E}+06$ & $9.38 \mathrm{E}+06$ & $2.38 \mathrm{E}+07$ \\
\hline & St. Dev & $9.64 \mathrm{E}+04$ & $3.99 \mathrm{E}+05$ & $7.68 \mathrm{E}+05$ & $1.14 \mathrm{E}+06$ & $6.03 \mathrm{E}+05$ & $1.58 \mathrm{E}+06$ & $5.21 \mathrm{E}+06$ \\
\hline \multirow{3}{*}{$\mathrm{F} 2$} & Min. & $2.00 \mathrm{E}+02$ & $2.03 \mathrm{E}+02$ & $2.05 \mathrm{E}+02$ & $5.91 \mathrm{E}+02$ & $2.03 \mathrm{E}+02$ & $2.02 \mathrm{E}+04$ & $6.03 \mathrm{E}+05$ \\
\hline & Max. & $1.09 \mathrm{E}+04$ & $3.15 \mathrm{E}+04$ & $3.36 \mathrm{E}+04$ & $3.49 \mathrm{E}+04$ & $3.40 \mathrm{E}+04$ & $2.74 \mathrm{E}+07$ & $1.77 \mathrm{E}+07$ \\
\hline & St. Dev & $3.95 \mathrm{E}+03$ & $9.63 \mathrm{E}+03$ & $1.15 \mathrm{E}+04$ & $9.99 \mathrm{E}+03$ & $1.37 \mathrm{E}+04$ & $5.76 \mathrm{E}+06$ & $4.37 \mathrm{E}+06$ \\
\hline \multirow{3}{*}{ F3 } & Min. & $3.00 \mathrm{E}+02$ & $3.20 \mathrm{E}+02$ & $3.20 \mathrm{E}+02$ & $3.20 \mathrm{E}+02$ & $3.20 \mathrm{E}+02$ & $3.20 \mathrm{E}+02$ & $3.20 \mathrm{E}+02$ \\
\hline & Max. & $3.20 \mathrm{E}+02$ & $3.20 \mathrm{E}+02$ & $3.21 \mathrm{E}+02$ & $3.21 \mathrm{E}+02$ & $3.20 \mathrm{E}+02$ & $3.20 \mathrm{E}+02$ & $3.21 \mathrm{E}+02$ \\
\hline & St. Dev & $3.03 \mathrm{E}+00$ & $8.23 \mathrm{E}-02$ & $1.27 \mathrm{E}-01$ & $1.29 \mathrm{E}-01$ & $5.91 \mathrm{E}-02$ & $4.72 \mathrm{E}-02$ & $1.30 \mathrm{E}-01$ \\
\hline \multirow{3}{*}{ F4 } & Min. & $4.02 \mathrm{E}+02$ & $4.03 \mathrm{E}+02$ & $4.03 \mathrm{E}+02$ & $4.21 \mathrm{E}+02$ & $4.16 \mathrm{E}+02$ & $4.08 \mathrm{E}+02$ & $4.19 \mathrm{E}+02$ \\
\hline & Max. & $4.23 \mathrm{E}+02$ & $4.21 \mathrm{E}+02$ & $4.31 \mathrm{E}+02$ & $4.37 \mathrm{E}+02$ & $4.75 \mathrm{E}+02$ & $4.33 \mathrm{E}+02$ & $5.04 \mathrm{E}+02$ \\
\hline & St. Dev & $3.76 \mathrm{E}+00$ & $4.50 \mathrm{E}+00$ & $7.94 \mathrm{E}+00$ & $4.49 \mathrm{E}+00$ & $1.34 \mathrm{E}+01$ & $6.09 \mathrm{E}+00$ & $1.74 \mathrm{E}+01$ \\
\hline \multirow{3}{*}{ F5 } & Min. & $5.07 \mathrm{E}+02$ & $5.07 \mathrm{E}+02$ & $5.07 \mathrm{E}+02$ & $5.51 \mathrm{E}+02$ & $6.22 \mathrm{E}+02$ & $8.26 \mathrm{E}+02$ & $1.00 \mathrm{E}+03$ \\
\hline & Max. & $2.52 \mathrm{E}+03$ & $1.46 \mathrm{E}+03$ & $1.46 \mathrm{E}+03$ & $1.43 \mathrm{E}+03$ & $2.09 \mathrm{E}+03$ & $1.51 \mathrm{E}+03$ & $2.17 \mathrm{E}+03$ \\
\hline & St. Dev & $1.65 \mathrm{E}+02$ & $2.53 \mathrm{E}+02$ & $2.17 \mathrm{E}+02$ & $2.41 \mathrm{E}+02$ & $3.32 \mathrm{E}+02$ & $1.60 \mathrm{E}+02$ & $2.82 \mathrm{E}+02$ \\
\hline \multirow{3}{*}{ F6 } & Min. & $7.59 \mathrm{E}+02$ & $7.12 \mathrm{E}+02$ & $7.98 \mathrm{E}+02$ & $8.30 \mathrm{E}+02$ & $6.50 \mathrm{E}+02$ & $1.39 \mathrm{E}+03$ & $2.80 \mathrm{E}+03$ \\
\hline & Max. & $1.15 \mathrm{E}+03$ & $6.22 \mathrm{E}+03$ & $8.29 \mathrm{E}+04$ & $1.02 \mathrm{E}+04$ & $1.10 \mathrm{E}+04$ & $9.29 \mathrm{E}+03$ & $1.38 \mathrm{E}+06$ \\
\hline & St. Dev & $5.05 \mathrm{E}+02$ & $1.28 \mathrm{E}+03$ & $2.02 \mathrm{E}+04$ & $2.89 \mathrm{E}+03$ & $3.94 \mathrm{E}+03$ & $2.14 \mathrm{E}+03$ & $4.13 \mathrm{E}+05$ \\
\hline \multirow{3}{*}{ F7 } & Min. & $7.00 \mathrm{E}+02$ & $7.00 \mathrm{E}+02$ & $7.01 \mathrm{E}+02$ & $7.01 \mathrm{E}+02$ & $7.02 \mathrm{E}+02$ & $7.02 \mathrm{E}+02$ & $7.03 \mathrm{E}+02$ \\
\hline & Max. & $7.02 \mathrm{E}+02$ & $7.04 \mathrm{E}+02$ & $7.05 \mathrm{E}+02$ & $7.04 \mathrm{E}+02$ & $7.06 \mathrm{E}+02$ & $7.03 \mathrm{E}+02$ & $7.10 \mathrm{E}+02$ \\
\hline & St. Dev & $2.95 \mathrm{E}-01$ & $8.12 \mathrm{E}-01$ & $7.62 \mathrm{E}-01$ & $4.61 \mathrm{E}-01$ & $1.23 \mathrm{E}+00$ & $3.76 \mathrm{E}-01$ & $1.40 \mathrm{E}+00$ \\
\hline \multirow{3}{*}{ F8 } & Min. & $8.18 \mathrm{E}+02$ & $8.23 \mathrm{E}+02$ & $1.09 \mathrm{E}+03$ & $8.21 \mathrm{E}+02$ & $8.23 \mathrm{E}+02$ & $1.20 \mathrm{E}+03$ & $1.44 \mathrm{E}+03$ \\
\hline & Max. & $3.91 \mathrm{E}+03$ & $1.39 \mathrm{E}+04$ & $5.39 \mathrm{E}+04$ & $2.63 \mathrm{E}+04$ & $2.56 \mathrm{E}+04$ & $4.32 \mathrm{E}+03$ & $2.62 \mathrm{E}+04$ \\
\hline & St. Dev & $7.18 \mathrm{E}+02$ & $3.89 \mathrm{E}+03$ & $1.36 \mathrm{E}+04$ & $8.97 \mathrm{E}+03$ & $5.78 \mathrm{E}+03$ & $7.23 \mathrm{E}+02$ & $5.92 \mathrm{E}+03$ \\
\hline \multirow{3}{*}{ F9 } & Min. & $1.00 \mathrm{E}+03$ & $1.00 \mathrm{E}+03$ & $1.00 \mathrm{E}+03$ & $1.00 \mathrm{E}+03$ & $1.00 \mathrm{E}+03$ & $1.00 \mathrm{E}+03$ & $1.00 \mathrm{E}+03$ \\
\hline & Max. & $1.00 \mathrm{E}+03$ & $1.00 \mathrm{E}+03$ & $1.00 \mathrm{E}+03$ & $1.00 \mathrm{E}+03$ & $1.11 \mathrm{E}+03$ & $1.00 \mathrm{E}+03$ & $1.00 \mathrm{E}+03$ \\
\hline & St. Dev & $4.58 \mathrm{E}-02$ & $8.78 \mathrm{E}-02$ & $1.83 \mathrm{E}-01$ & $5.99 \mathrm{E}-02$ & $1.80 \mathrm{E}+01$ & $1.53 \mathrm{E}-01$ & $2.94 \mathrm{E}-01$ \\
\hline \multirow{3}{*}{ F10 } & Min. & $1.33 \mathrm{E}+03$ & $1.34 \mathrm{E}+03$ & $1.75 \mathrm{E}+03$ & $1.25 \mathrm{E}+03$ & $1.45 \mathrm{E}+03$ & $1.66 \mathrm{E}+03$ & $1.81 \mathrm{E}+03$ \\
\hline & Max. & $3.09 \mathrm{E}+03$ & $9.01 \mathrm{E}+03$ & $3.72 \mathrm{E}+04$ & $3.47 \mathrm{E}+04$ & $1.65 \mathrm{E}+04$ & $7.19 \mathrm{E}+03$ & $5.49 \mathrm{E}+04$ \\
\hline & St. Dev & $1.24 \mathrm{E}+03$ & $1.79 \mathrm{E}+03$ & $8.24 \mathrm{E}+03$ & $7.46 \mathrm{E}+03$ & $4.28 \mathrm{E}+03$ & $1.29 \mathrm{E}+03$ & $1.41 \mathrm{E}+04$ \\
\hline \multirow{3}{*}{ F11 } & Min. & $1.10 \mathrm{E}+03$ & $1.10 \mathrm{E}+03$ & $1.11 \mathrm{E}+03$ & $1.11 \mathrm{E}+03$ & $1.12 \mathrm{E}+03$ & $1.11 \mathrm{E}+03$ & $1.11 \mathrm{E}+03$ \\
\hline & Max. & $1.30 \mathrm{E}+03$ & $1.63 \mathrm{E}+03$ & $1.59 \mathrm{E}+03$ & $1.58 \mathrm{E}+03$ & $1.65 \mathrm{E}+03$ & $1.41 \mathrm{E}+03$ & $1.77 \mathrm{E}+03$ \\
\hline & St. Dev & $2.33 \mathrm{E}+01$ & $8.11 \mathrm{E}+01$ & $1.19 \mathrm{E}+02$ & $7.75 \mathrm{E}+01$ & $8.24 \mathrm{E}+01$ & $1.21 \mathrm{E}+02$ & $1.41 \mathrm{E}+02$ \\
\hline \multirow{3}{*}{ F12 } & Min. & $1.30 \mathrm{E}+03$ & $1.30 \mathrm{E}+03$ & $1.30 \mathrm{E}+03$ & $1.30 \mathrm{E}+03$ & $1.30 \mathrm{E}+03$ & $1.30 \mathrm{E}+03$ & $1.30 \mathrm{E}+03$ \\
\hline & Max. & $1.30 \mathrm{E}+03$ & $1.30 \mathrm{E}+03$ & $1.30 \mathrm{E}+03$ & $1.30 \mathrm{E}+03$ & $1.31 \mathrm{E}+03$ & $1.31 \mathrm{E}+03$ & $1.32 \mathrm{E}+03$ \\
\hline & St. Dev & $8.08 \mathrm{E}-01$ & $8.46 \mathrm{E}-01$ & $8.74 \mathrm{E}-01$ & $4.48 \mathrm{E}-01$ & $2.07 \mathrm{E}+00$ & $1.16 \mathrm{E}+00$ & $3.96 \mathrm{E}+00$ \\
\hline \multirow{3}{*}{ F13 } & Min. & $1.30 \mathrm{E}+03$ & $1.30 \mathrm{E}+03$ & $1.30 \mathrm{E}+03$ & $1.30 \mathrm{E}+03$ & $1.30 \mathrm{E}+03$ & $1.30 \mathrm{E}+03$ & $1.30 \mathrm{E}+03$ \\
\hline & Max. & $1.30 \mathrm{E}+03$ & $1.30 \mathrm{E}+03$ & $1.30 \mathrm{E}+03$ & $1.30 \mathrm{E}+03$ & $1.30 \mathrm{E}+03$ & $1.30 \mathrm{E}+03$ & $1.30 \mathrm{E}+03$ \\
\hline & St. Dev & $1.76 \mathrm{E}-04$ & $6.82 \mathrm{E}-03$ & $1.47 \mathrm{E}-03$ & $2.94 \mathrm{E}-04$ & $3.64 \mathrm{E}-03$ & $1.24 \mathrm{E}-03$ & $5.48 \mathrm{E}-03$ \\
\hline \multirow{3}{*}{ F14 } & Min. & $1.50 \mathrm{E}+03$ & $1.50 \mathrm{E}+03$ & $4.33 \mathrm{E}+03$ & $4.34 \mathrm{E}+03$ & $1.50 \mathrm{E}+03$ & $1.55 \mathrm{E}+03$ & $4.37 \mathrm{E}+03$ \\
\hline & Max. & $7.15 \mathrm{E}+03$ & $1.19 \mathrm{E}+04$ & $1.19 \mathrm{E}+04$ & $1.14 \mathrm{E}+04$ & $1.29 \mathrm{E}+04$ & $8.51 \mathrm{E}+03$ & $8.57 \mathrm{E}+03$ \\
\hline & St. Dev & $9.88 \mathrm{E}+02$ & $2.72 \mathrm{E}+03$ & $2.27 \mathrm{E}+03$ & $2.63 \mathrm{E}+03$ & $2.91 \mathrm{E}+03$ & $1.44 \mathrm{E}+03$ & $1.44 \mathrm{E}+03$ \\
\hline \multirow{3}{*}{ F15 } & Min. & $1.60 \mathrm{E}+03$ & $1.60 \mathrm{E}+03$ & $1.60 \mathrm{E}+03$ & $1.60 \mathrm{E}+03$ & $1.60 \mathrm{E}+03$ & $1.60 \mathrm{E}+03$ & $1.60 \mathrm{E}+03$ \\
\hline & Max. & $1.60 \mathrm{E}+03$ & $1.60 \mathrm{E}+03$ & $1.60 \mathrm{E}+03$ & $1.61 \mathrm{E}+03$ & $1.60 \mathrm{E}+03$ & $1.60 \mathrm{E}+03$ & $1.61 \mathrm{E}+03$ \\
\hline & St. Dev & $8.41 \mathrm{E}-12$ & $1.11 \mathrm{E}-11$ & $3.41 \mathrm{E}-12$ & $8.20 \mathrm{E}-01$ & $5.20 \mathrm{E}-13$ & $6.70 \mathrm{E}-01$ & $3.37 \mathrm{E}+00$ \\
\hline
\end{tabular}


Table 8. Average error rates of the algorithms obtained in mathematical test functions.

\begin{tabular}{cccccccc}
\hline \multirow{2}{*}{ Function } & \multicolumn{7}{c}{ Algorithm } \\
\cline { 2 - 8 } & Present work & PSO & CBO & ECBO & WCA & LOA & WOA \\
\hline F1 & 46755.922 & 316255.297 & 927865.185 & 681181.529 & 271115.021 & 1885622.710 & 7615642.072 \\
F2 & 4802.406 & 10030.057 & 11700.583 & 10220.590 & 10831.886 & 4017996.482 & 6194263.355 \\
F3 & 18.028 & 20.356 & 20.392 & 20.419 & 20.027 & 20.235 & 20.193 \\
F4 & 15.972 & 10.070 & 15.060 & 28.708 & 37.446 & 19.249 & 49.496 \\
F5 & 400.033 & 400.756 & 434.061 & 390.749 & 1019.646 & 761.286 & 1048.991 \\
F6 & 429.211 & 1263.613 & 14949.533 & 3091.745 & 4815.625 & 3025.786 & 329233.543 \\
F7 & 1.058 & 1.509 & 2.233 & 2.350 & 3.303 & 2.338 & 6.207 \\
F8 & 1490.274 & 4504.074 & 13539.852 & 8455.109 & 4348.638 & 1470.065 & 6218.680 \\
F9 & 100.211 & 100.281 & 100.473 & 100.416 & 103.648 & 100.574 & 100.723 \\
F10 & 999.446 & 1882.728 & 9127.900 & 5307.194 & 3877.947 & 2091.119 & 12630.115 \\
F11 & 43.055 & 299.089 & 270.649 & 317.711 & 315.165 & 226.392 & 357.387 \\
F12 & 101.471 & 102.519 & 101.730 & 103.213 & 105.660 & 104.614 & 108.898 \\
F13 & 0.030 & 0.069 & 0.031 & 0.032 & 0.032 & 0.032 & 0.036 \\
F14 & 1954.700 & 6332.226 & 6068.181 & 5450.378 & 5491.305 & 2964.175 & 6374.899 \\
F15 & 100.000 & 100.000 & 100.000 & 104.530 & 100.000 & 100.988 & 104.733 \\
\hline
\end{tabular}
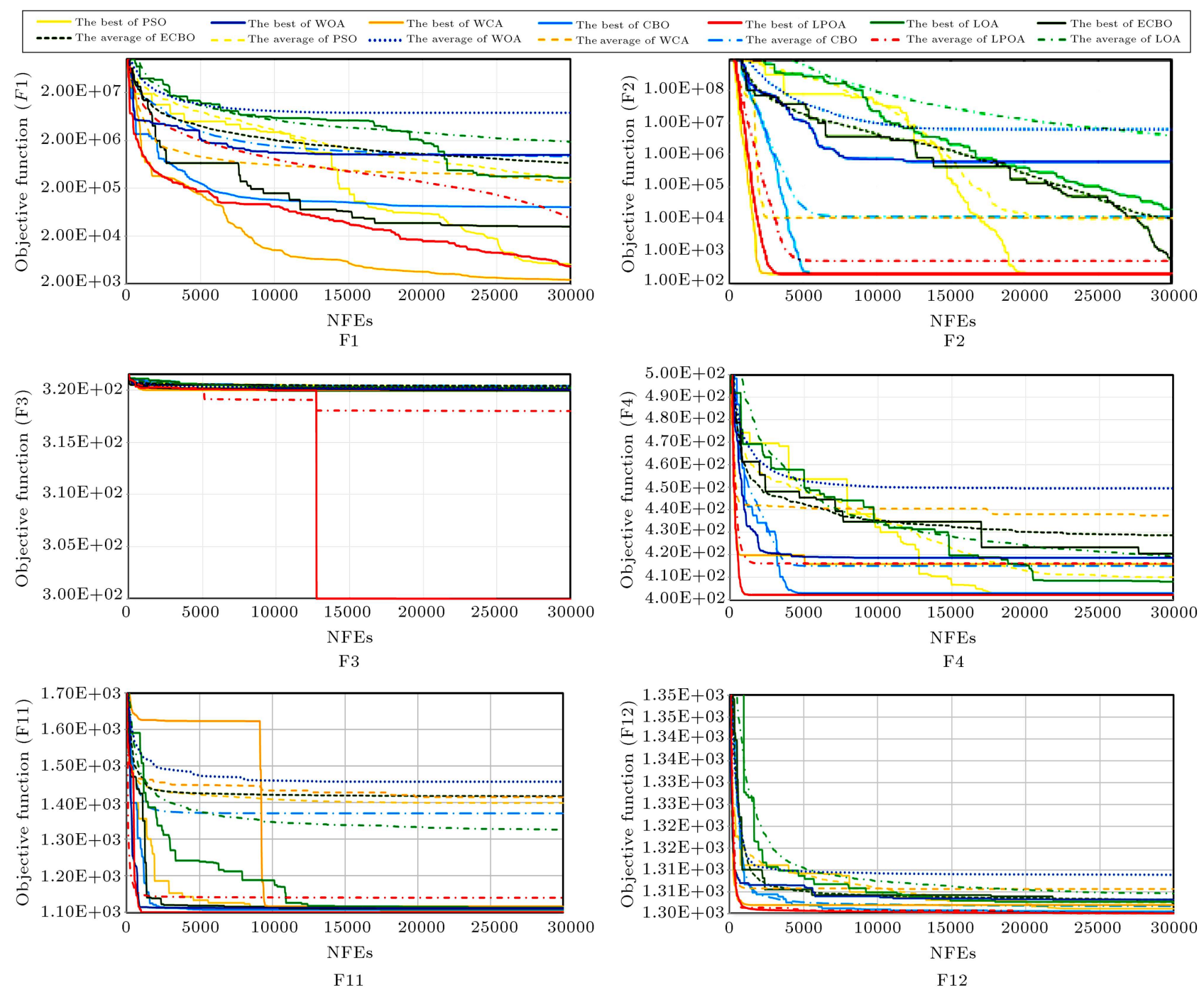

Figure 7. Comparative convergence curves obtained from the selected algorithms for mathematical functions. 
Table 9. Friedman test results for comparing the proposed methods with other algorithms on 15 mathematical datasets.

\begin{tabular}{cc} 
Algorithm & Rank \\
\hline Present work & 1.3667 \\
PSO & 3.2333 \\
CBO & 4.1667 \\
ECBO & 4.3333 \\
WCA & 4.4333 \\
LOA & 4 \\
WOA & 6.4667 \\
\hline
\end{tabular}

zero; otherwise, the value of the penalty is calculated by dividing the violation of the allowable limit by the limit itself. The constraint violation penalty can be stated as follows:

$$
f_{\text {penalty }}(x)=\left(1+\varepsilon_{1} \times v\right)^{\varepsilon_{2}}, \quad v=\sum_{i=1}^{c} v_{i} .
$$

$v$ is violation ratio that is defined as in Eq. (19), and $c$ is the number of constraints where $\varepsilon_{1}$ and $\varepsilon_{2}$ are parameters that penalize the unfeasible solutions more severely. $\varepsilon_{1}$ is taken as unity, and $\varepsilon_{2}$ starts from 1.5 and linearly increases to 6 in all design problems.

If the constraint is satisfied : $v_{i}=0$,

If the constraint is violated $: v_{i}=\left|1-\frac{b_{i}^{*}}{b_{i}}\right|$,

where $b_{i}^{*}$ is the upper bound constraint boundary value, and $b_{i}$ is the value of the related property value of the structure. Penalized fitness is introduced as follows:

$$
P(x)=f(x) \times f_{\text {penalty }}(x),
$$

where $f(x)$ is the fitness function, which generally is taken as the weight of the structure in a design optimization problem.

The examples considered from the literature include:
Table 11. Parameter values of the LPOA in design functions.

\begin{tabular}{lc}
\hline \multicolumn{1}{c}{ Parameter } & Value \\
\hline Number of prides & $3-7$ \\
Lions in each prides & $4-7$ \\
Male lions in each prides & $1-2$ \\
Female lions in each prides & $3-6$ \\
Territory ratio & 0.2 \\
Mating probability & 0.1 \\
Immigration rate & 0.2 \\
Diversification factor & 0.1 to 0.0001 \\
\hline
\end{tabular}

- A pressure vessel design;

- A 52-bar planar truss design;

- A 72-bar spatial truss design.

Parameter values of LPOA in the evaluation of structural benchmark problems are depicted in Table 11.

\subsection{A 52-bar planar truss design}

The 52-bar planar truss is depicted in Figure 8 schematically. The members of this structure are divided into 12 groups: (1) A1-A4, (2) A5-A10, (3) A11-A13, (4) A14-A17, (5) A18-A23, (6) A24-A26, (7) A27-A30, (8) A31-A36, (9) A37-A39, (10) A40A43, (11) A44-A49, and (12) A50-A52. The material density is $7860.0 \mathrm{~kg} / \mathrm{m}^{3}$, and the modulus of elasticity is $2.07 \times 10^{5} \mathrm{MPa}$. The members are subjected to stress limitations of $\pm 180 \mathrm{MPa}$. Both loads, $p_{x}=100 \mathrm{kN}$ and $p_{y}=200 \mathrm{kN}$, are considered, and the discrete variables are selected from Table 12.

This benchmark example has been optimized by different researchers; Lee and Geem [41] designed the problem by employing a harmony search algorithm. $\mathrm{Li}$ et al. [42] utilized the particle swarm optimization algorithm and the heuristic particle swarm optimizer to solve the design problem; $\mathrm{Wu}$ and Chow [43] found the solution of the problem by implementing the steady-state genetic algorithm; Sadollah et al. [9] carried out the optimized design using Mine Blast

Table 10. $z$-value, unadjusted and adjusted $p$-values for the Friedman test (LPOA is the control method).

\begin{tabular}{ccccccccc}
\hline Algorithm & $\boldsymbol{z}$ & Unadjusted $\boldsymbol{p}$ & $\mathbf{p H o l m}$ & pRom & pHommel & pFinner & pHolland & pLi \\
\hline WOA & 6.4654 & 0.0000 & 0.0000 & 0.0000 & 0.0000 & 0.0000 & 0.0000 & 0.0000 \\
WCA & 3.8877 & 0.0001 & 0.0005 & 0.0005 & 0.0004 & 0.0003 & 0.0005 & 0.0001 \\
ECBO & 3.7609 & 0.0002 & 0.0007 & 0.0006 & 0.0007 & 0.0003 & 0.0007 & 0.0002 \\
CBO & 3.5496 & 0.0004 & 0.0012 & 0.0012 & 0.0012 & 0.0006 & 0.0012 & 0.0004 \\
LOA & 3.3384 & 0.0008 & 0.0017 & 0.0017 & 0.0017 & 0.0010 & 0.0017 & 0.0009 \\
PSO & 2.3664 & 0.0180 & 0.0180 & 0.0180 & 0.0180 & 0.0180 & 0.0180 & 0.0180 \\
\hline
\end{tabular}




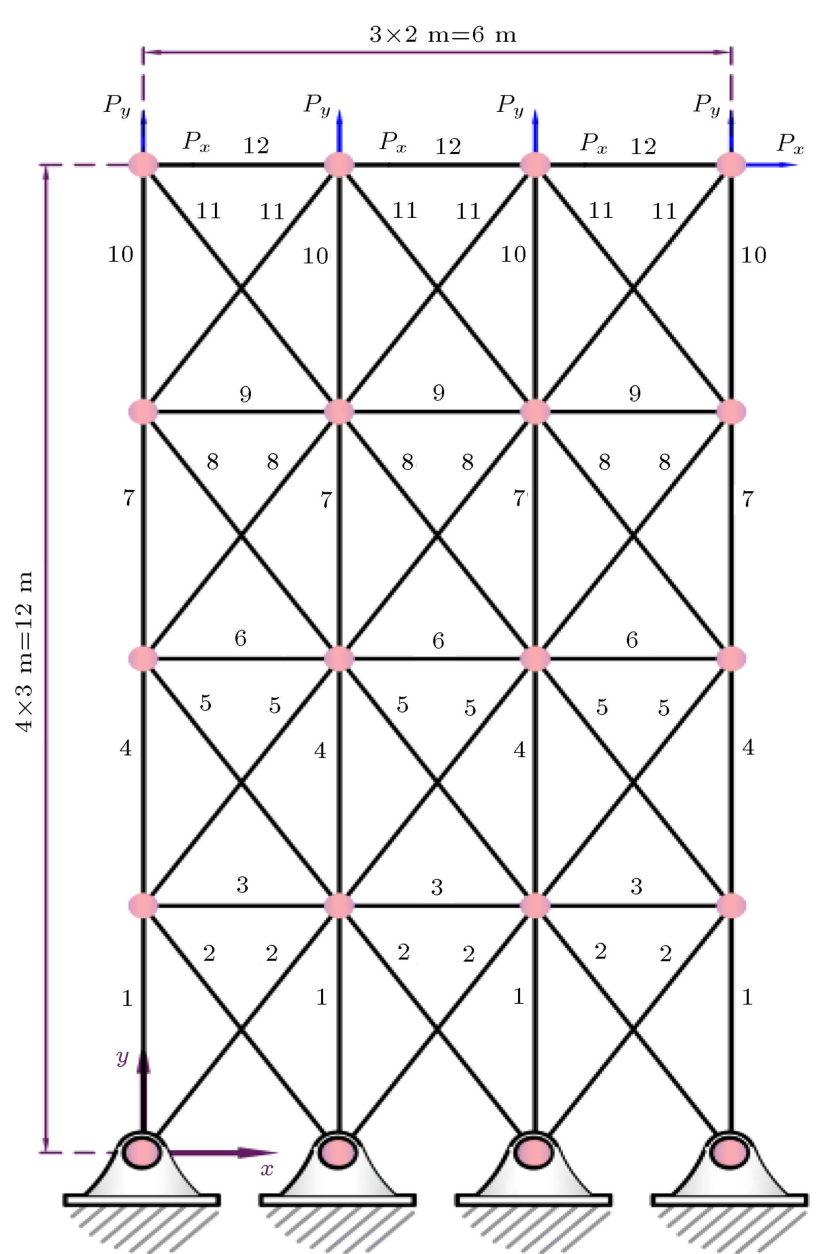

Figure 8. Schematic of a 52-bar planar truss.

Algorithm (MBA), while Cheng and Prayogo [44] as well as Mirjalili and Lewis [30] implemented symbiotic organisms (SOS) and Whale Optimization Algorithm (WOA) to solve the 52-bar planar truss design problem, respectively.

The LPOA proceeds until the maximum number of 300 iterations. Here, 20 search agents are utilized for solving the design problem, and 20 individual optimization runs have been carried out for this benchmark example. The corresponding results are presented in Table 13. The answers are rounded to the nearest integer number during the implementation of the optimization algorithm, since the variables of the problem are discrete. In accordance with the results, it can be seen that the best optimal answer is obtained by the LPOA, which is equal to $1902.28 \mathrm{~kg}$ achieved in 5980 analyses. In addition, the average and standard deviations of 20 individual optimal solutions exploited by the proposed algorithm are $1944.3478 \mathrm{~kg}$ and $54.8133 \mathrm{~kg}$, respectively. The results show that the LPOA has better performance than other mentioned algorithms' performance in finding the best optimal solutions.

The stress ratios and stress values of two solutions
Table 12. The available cross-section areas of the AISC code.

\begin{tabular}{cccccccc}
\hline No. & in. $^{2}$ & No. & in. $^{2}$ & No. & in. $^{2}$ & No. & in. $^{2}$ \\
\hline 1 & 0.111 & 17 & 1.563 & 33 & 3.84 & 49 & 11.5 \\
2 & 0.141 & 18 & 1.62 & 34 & 3.87 & 50 & 13.5 \\
3 & 0.196 & 19 & 1.8 & 35 & 3.88 & 51 & 13.9 \\
4 & 0.25 & 20 & 1.99 & 36 & 4.18 & 52 & 14.2 \\
5 & 0.307 & 21 & 2.13 & 37 & 4.22 & 53 & 15.5 \\
6 & 0.391 & 22 & 2.38 & 38 & 4.49 & 54 & 16 \\
7 & 0.442 & 23 & 2.62 & 39 & 4.59 & 55 & 16.9 \\
8 & 0.563 & 24 & 2.63 & 40 & 4.8 & 56 & 18.8 \\
9 & 0.602 & 25 & 2.88 & 41 & 4.97 & 57 & 19.9 \\
10 & 0.766 & 26 & 2.93 & 42 & 5.12 & 58 & 22 \\
11 & 0.785 & 27 & 3.09 & 43 & 5.74 & 59 & 22.9 \\
12 & 0.994 & 28 & 1.13 & 44 & 7.22 & 60 & 24.5 \\
13 & 1 & 29 & 3.38 & 45 & 7.97 & 61 & 26.5 \\
14 & 1.228 & 30 & 3.47 & 46 & 8.53 & 62 & 28 \\
15 & 1.266 & 31 & 3.55 & 47 & 9.3 & 63 & 30 \\
16 & 1.457 & 32 & 3.63 & 48 & 10.85 & 64 & 33.5 \\
\hline & & & & & & &
\end{tabular}

of LPOA and IMCSS and stress values in each member are shown in Figures 9 and 10, respectively. Moreover, the convergence curves of the LPOA are provided in Figure 11.

\subsection{A 72-bar spatial truss}

A 72-bar spatial truss structure is depicted in Figure 12. The material density is $0.1 \mathrm{lb} / \mathrm{in}^{3}$ $\left(2,767.990 \mathrm{~kg} / \mathrm{m}^{3}\right)$, and the modulus of elasticity is $10,000 \mathrm{ksi}(68,950 \mathrm{MPa})$ in this example. The nodes are subjected to the displacement limits of 0.25 in $(0.635 \mathrm{~cm})$, and the elements are subjected to the stress limits of $25 \mathrm{ksi}(172.375 \mathrm{MPa})$.

Then, 72 members of the structure are classified into 16 variable groups: (1) A1-A4, (2) A5-A12, (3) A13-A16, (4) A17-A18, (5) A19-A22, (6) A23-A30, (7) A31-A34, (8) A35-A36, (9) A37-A40, (10) A41-A48, (11) A49-A52, (12) A53-A54, (13) A55-A58, (14) A59A66 (15), A67-A70, and (16) A71-A72.

Two different optimization case studies are implemented as follows:

Case 1: The discrete variables are selected from the set $D=[0.1,0.2,0.3,0.4,0.5,0.6,0.7,0.8,0.9,1.0$, $1.1,1.2,1.3,1.4,1.5,1.6,1.7,1.8,1.9,2.0,2.1,2.2$, $2.3,2.4,2.5,2.6,2.7,2.8,2.9,3.0,3.1,3.2]\left(\mathrm{in}^{2}\right)$. In addition, Load Case 1 is applied to the truss, as depicted in Table 14;

Case 2: The discrete variables are selected from 
Table 13. Optimized designs obtained for the 52-bar planar truss.

\begin{tabular}{|c|c|c|c|c|c|c|c|c|c|c|c|c|c|}
\hline \multirow{2}{*}{ Algorithm } & \multicolumn{12}{|c|}{ Element group variables $\left(\mathrm{mm}^{2}\right)$} & \multirow{2}{*}{$\begin{array}{c}\text { Weight } \\
(\mathbf{k g})\end{array}$} \\
\hline & 1 & 2 & 3 & 4 & 5 & 6 & 7 & 8 & 9 & 10 & 11 & 12 & \\
\hline $\begin{array}{c}\text { Present } \\
\text { work }\end{array}$ & 4360.45 & 1161.29 & 285.16 & 3703.22 & 940.00 & 494.19 & 2290.32 & 1008.39 & 388.39 & 1283.87 & 1161.29 & 494.19 & 1902 \\
\hline HS [41] & 5 & 1161.29 & 506.45 & 3303.22 & 940.00 & 494.19 & 2290.32 & 1008.39 & 2290.32 & 1535.48 & 1045.16 & 506.45 & 1906.76 \\
\hline PSO [42] & 4658.06 & 1374.19 & 1858.06 & 3206.44 & 1283.87 & 252.26 & 3303.22 & 1045.16 & 126.45 & 2341.93 & 1008.38 & 1045.16 & 2230.16 \\
\hline HPSO [42] & 4658.06 & 1161.29 & 363.23 & 3303.22 & 940.00 & 494.19 & 2238.71 & 1008.39 & 388.39 & 1283.87 & & 792.26 & 1905.495 \\
\hline MBA $[9]$ & 4658.06 & 1161.29 & 494.19 & 3303.22 & 940.00 & 494.19 & 2238.71 & 1008.39 & 494.19 & 1283.87 & 1161.29 & 494.19 & 1902.605 \\
\hline SOS $[44]$ & 4658 & 1161.29 & 494.19 & 3303.22 & 940.00 & 494.19 & 2238.71 & 1008.39 & 494.19 & 128 & 116 & 494.19 & 1902 \\
\hline WOA [30] & 4658.06 & 1161.29 & 494.19 & 3303.22 & 940.00 & 494.19 & 2238.71 & 1008.39 & 494.19 & 1283.87 & 1161.29 & 494.19 & 1902.605 \\
\hline GA [43] & 4658.06 & 1161.29 & 645.16 & 3303.22 & 1045.16 & 494.19 & 2477.141 & 1045.16 & 285.16 & 1696.77 & 1045.16 & 641.29 & 1970 \\
\hline
\end{tabular}

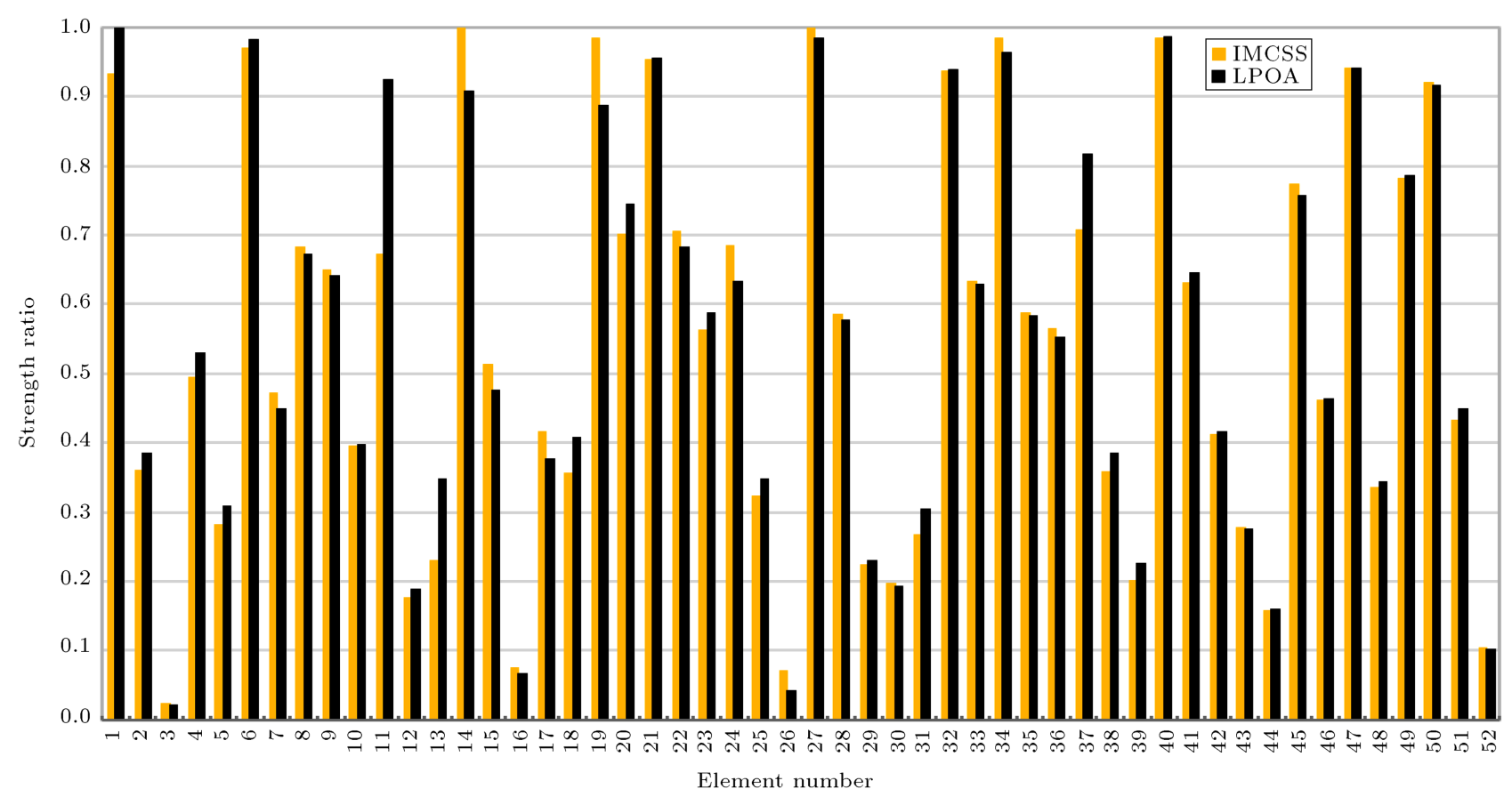

Figure 9. Member stress ratios of the best solution obtained by LPOA and IMCSS.

AISC code cross-sections as illustrated in Table 12, and Load Case 2 applied to the truss is shown in Table 14.

The 72-bar spatial truss problem has been studied by many researchers and, also, with different algorithms. Wu and Chow used Genetic Algorithm (GA) [43]; Li et al. [45] utilized Particle Swarm Optimization (PSO), Particle Swarm Optimizer with Passive Congregation (PSOPC), and Heuristic Particle Swarm Optimizer (HPSO); Kaveh and Farhoudi [46] employed Dolphin Echolocation (DE); Cheng et al. [47] used Hybrid Harmony Search (HHS) algorithm; Sadollah et al. [9] imposed Mine Blast Algorithm (MBA) to solve this benchmark problem.
Table 14. Load cases applied to the 72-bar spatial truss structure.

\begin{tabular}{ccccccccc}
\hline \multirow{2}{*}{ Node } & \multicolumn{3}{c}{ Case 1 (kips) } & & \multicolumn{3}{c}{ Case 2 (kips) } \\
\cline { 2 - 3 } \cline { 7 - 8 } & $\boldsymbol{P}_{\boldsymbol{X}}$ & $\boldsymbol{P}_{\boldsymbol{Y}}$ & $\boldsymbol{P}_{\boldsymbol{Z}}$ & & $\boldsymbol{P}_{\boldsymbol{X}}$ & $\boldsymbol{P}_{\boldsymbol{Y}}$ & $\boldsymbol{P}_{\boldsymbol{Z}}$ \\
\hline 17 & 5.0 & 5.0 & 5.0 & & 0.0 & 0.0 & 5.0 \\
18 & 0.0 & 0.0 & 0.0 & & 0.0 & 0.0 & 5.0 \\
19 & 0.0 & 0.0 & 0.0 & & 0.0 & 0.0 & 5.0 \\
20 & 0.0 & 0.0 & 0.0 & & 0.0 & 0.0 & 5.0 \\
\hline
\end{tabular}

It employed 50 search agents over 200 iterations and 20 independent runs for solving each case of the problem. The LPOA comparative solutions of the two loading cases are given in Tables 15 and 16, respectively. 


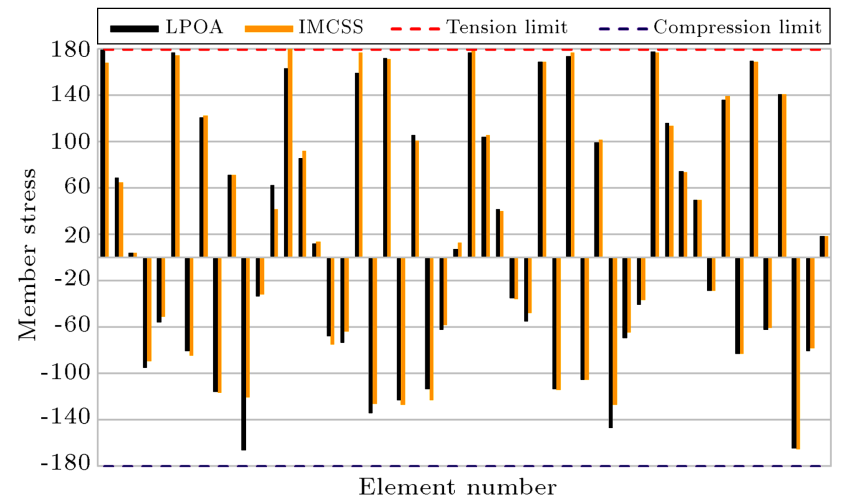

Figure 10. Member stresses of the best solution obtained by LPOA and IMCSS.

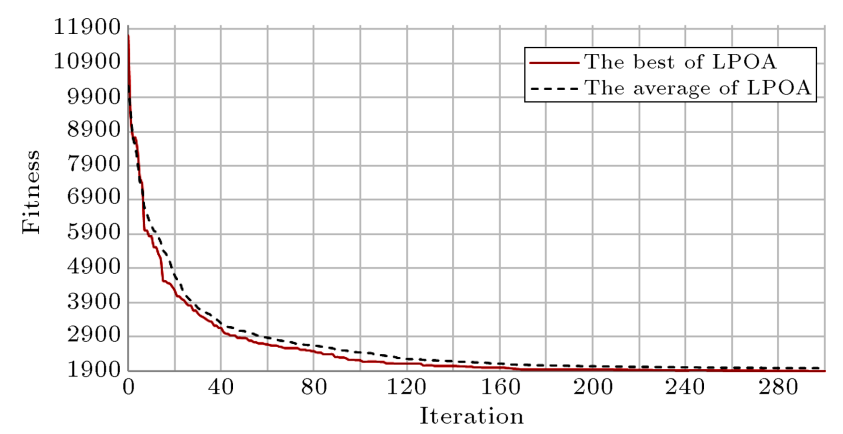

Figure 11. Convergence curves obtained for the 52-bar planar truss problem.

Based on Tables 15 and 16, LPOA found better results than the mentioned algorithms did, in these two case studies. The standard deviation and the average of the best solution obtained in the last iteration in the first case of study were $3.8167 \mathrm{lb}$ and $373.6517 \mathrm{lb}$, respectively. In addition, in the second case, the standard deviation and average are obtained as $2.8360 \mathrm{lb}$ and $389.5500 \mathrm{lb}$, respectively.

Of note, the standard deviation of the results by the LPOA in 20 independent runs is very small in both case studies, and the average of the solutions obtained by LPOA is less than those of the existing results from literature. The convergence histories of the LPOA are presented in Figures 13 and 14.

\section{Conclusions}

A new population-based optimization algorithm was introduced in this paper, called pride lion optimization algorithm, to provide a sufficiently good solution to mathematical and structural problems. The fundamental concepts and ideas for the codification of this method were derived from the behavior of lions in a pride. The proposed method contained two types of search agents (lions and lionesses) with a specific set of characteristics. Hunting, excursion of lions in territories, intra-group interactions, and mating behaviors were simulated in the proposed algorithm.

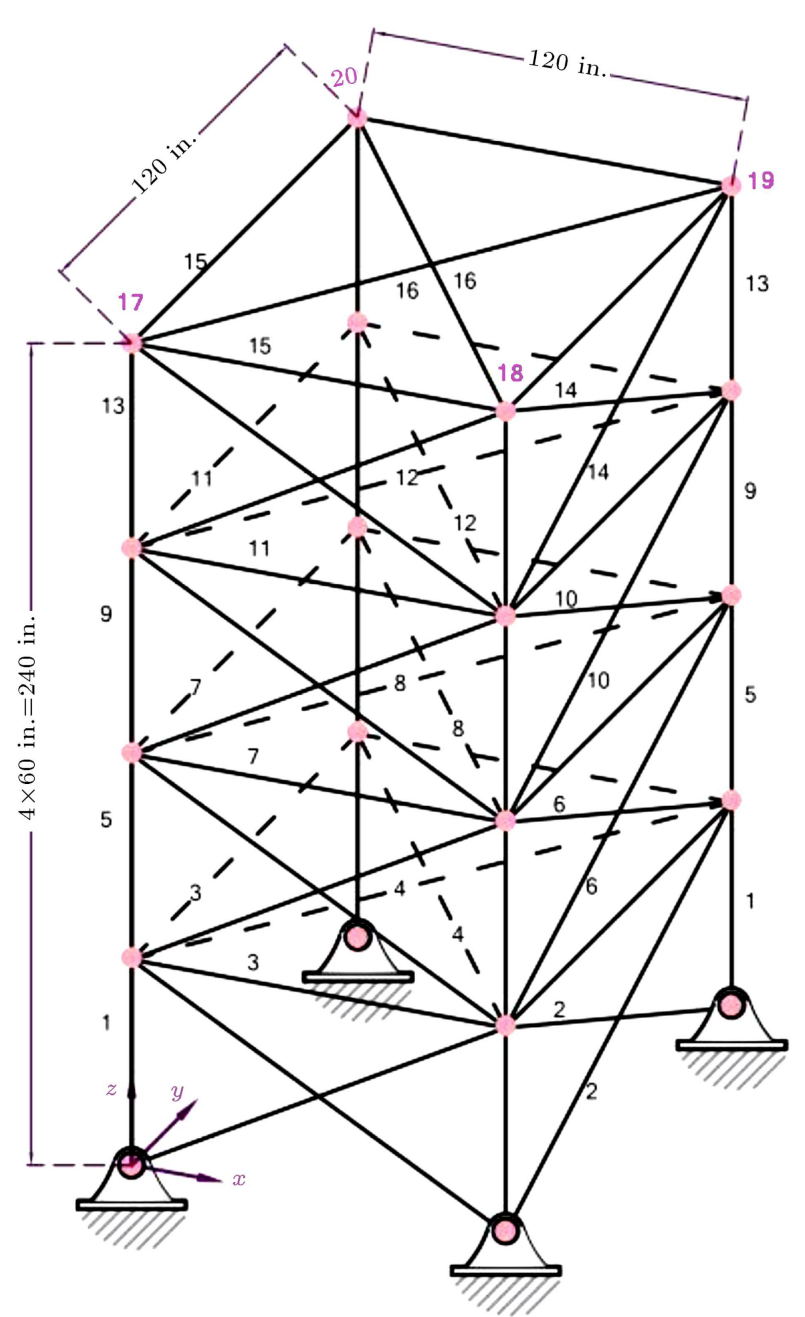

Figure 12. Schematic of a 72-bar spatial truss.

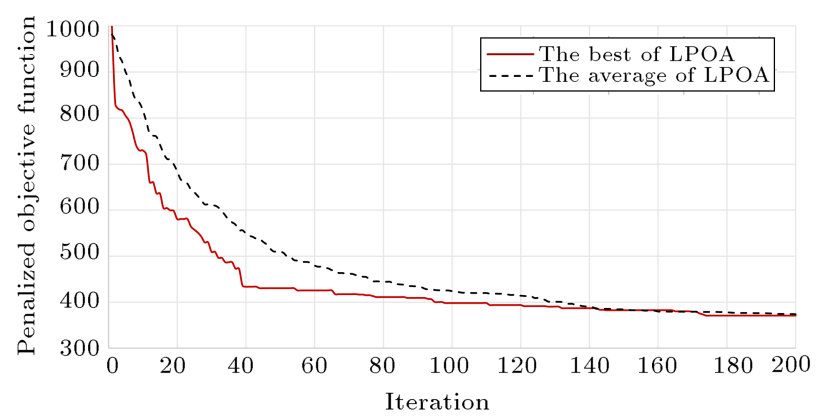

Figure 13. Convergence curves for the first case of the 72-bar spatial truss problem (Case 1 ).

In addition, a set of 15 benchmark-unconstrained functions with specific characteristics was tested and analyzed in comparison to other existing methods. The mathematical functions were categorized as four types of functions: unimodal, hybrid, multimodal, and composite.

In addition, sensitivity analysis of the parameters was performed to evaluate how these parameters influenced the performance of the algorithm. The Friedman 
Table 15. Optimal design comparison for the spatial 72-bar spatial truss problem (Case 1).

\begin{tabular}{ccccccccc}
\hline \multirow{2}{*}{ Element group } & \multicolumn{7}{c}{ Optimal cross-sectional areas $\left(\mathbf{i n}^{2}\right)$} \\
\cline { 2 - 8 } & $\begin{array}{c}\text { Present } \\
\text { work }\end{array}$ & $\begin{array}{c}\text { GA } \\
{[\mathbf{4 3}]}\end{array}$ & $\begin{array}{c}\text { PSO } \\
{[\mathbf{4 5}]}\end{array}$ & $\begin{array}{c}\text { PSOPC } \\
{[\mathbf{4 5}]}\end{array}$ & $\begin{array}{c}\text { HPSO } \\
{[\mathbf{4 5}]}\end{array}$ & $\begin{array}{c}\text { HHS } \\
{[\mathbf{4 7}]}\end{array}$ & $\begin{array}{c}\text { DE } \\
{[\mathbf{4 6}]}\end{array}$ & $\begin{array}{c}\text { MBA } \\
{[\mathbf{9}]}\end{array}$ \\
\hline 1 & 1.8 & 1.5 & 2.6 & 3 & 2.1 & 1.9 & 2 & 2.0 \\
2 & 0.5 & 0.7 & 1.5 & 1.4 & 0.6 & 0.5 & 0.5 & 0.6 \\
3 & 0.1 & 0.1 & 0.3 & 0.2 & 0.1 & 0.1 & 0.1 & 0.4 \\
4 & 0.1 & 0.1 & 0.1 & 0.1 & 0.1 & 0.1 & 0.1 & 0.6 \\
5 & 1.3 & 1.3 & 2.1 & 2.7 & 1.4 & 1.4 & 1.3 & 0.5 \\
6 & 0.5 & 0.5 & 1.5 & 1.9 & 0.5 & 0.5 & 0.5 & 0.5 \\
7 & 0.1 & 0.2 & 0.6 & 0.7 & 0.1 & 0.1 & 0.1 & 0.1 \\
8 & 0.1 & 0.1 & 0.3 & 0.8 & 0.1 & 0.1 & 0.1 & 0.1 \\
9 & 0.5 & 0.5 & 2.2 & 1.4 & 0.5 & 0.5 & 0.5 & 1.4 \\
10 & 0.5 & 0.5 & 1.9 & 1.2 & 0.5 & 0.5 & 0.5 & 0.5 \\
11 & 0.1 & 0.1 & 0.2 & 0.8 & 0.1 & 0.1 & 0.1 & 0.1 \\
12 & 0.1 & 0.2 & 0.9 & 0.1 & 0.1 & 0.1 & 0.1 & 0.1 \\
13 & 0.1 & 0.2 & 0.4 & 0.4 & 0.2 & 0.2 & 0.2 & 1.9 \\
14 & 0.5 & 0.5 & 1.9 & 1.9 & 0.5 & 0.6 & 0.6 & 0.5 \\
15 & 0.4 & 0.5 & 0.7 & 0.9 & 0.3 & 0.4 & 0.4 & 0.1 \\
Weight (lb) & 371.0037 & 400.66 & 1089.88 & 1069.79 & 388.94 & 385.54 & 385.54 & 385.54
\end{tabular}

Table 16. Optimal design comparison for the spatial 72-bar spatial truss problem (Case 2).

\begin{tabular}{cccccccc}
\hline \multirow{2}{*}{ Element group } & \multicolumn{7}{c}{ Optimal cross-sectional areas $\left(\mathbf{i n}^{2}\right)$} \\
\cline { 2 - 7 } & $\begin{array}{c}\text { Present } \\
\text { work }\end{array}$ & GA & PSO & PSOPC & HPSO & DE & MBA \\
\hline 1 & 2.13 & 0.196 & 7.22 & 4.49 & 4.97 & 2.13 & 0.196 \\
2 & 0.563 & 0.602 & 1.8 & 1.457 & 1.228 & 0.442 & 0.563 \\
3 & 0.111 & 0.307 & 1.13 & 0.111 & 0.111 & 0.111 & 0.442 \\
4 & 0.111 & 0.766 & 0.2 & 0.111 & 0.111 & 0.111 & 0.602 \\
5 & 1.563 & 0.391 & 3.09 & 2.62 & 2.88 & 1.457 & 0.442 \\
6 & 0.442 & 0.391 & 0.79 & 1.13 & 1.457 & 0.563 & 0.442 \\
7 & 0.111 & 0.141 & 0.56 & 0.196 & 0.141 & 0.111 & 0.111 \\
8 & 0.111 & 0.111 & 0.79 & 0.111 & 0.111 & 0.111 & 0.111 \\
9 & 0.563 & 1.8 & 3.09 & 1.266 & 1.563 & 0.442 & 1.266 \\
10 & 0.442 & 0.602 & 1.23 & 1.457 & 1.228 & 0.563 & 0.563 \\
11 & 0.111 & 0.141 & 0.11 & 0.111 & 0.111 & 0.111 & 0.111 \\
12 & 0.111 & 0.307 & 0.56 & 0.111 & 0.196 & 0.111 & 0.111 \\
13 & 0.141 & 1.563 & 0.99 & 0.442 & 0.391 & 0.196 & 1.800 \\
14 & 0.563 & 0.766 & 1.62 & 1.457 & 1.457 & 0.563 & 0.602 \\
15 & 0.391 & 0.141 & 1.56 & 1.228 & 0.766 & 0.307 & 0.111 \\
16 & 0.563 & 0.111 & 1.27 & 1.457 & 1.563 & 0.563 & 0.111 \\
Weight(1b) & 386.4270 & 427.203 & 1209 & 941.82 & 933.09 & 391.329 & 390.73 \\
\hline
\end{tabular}




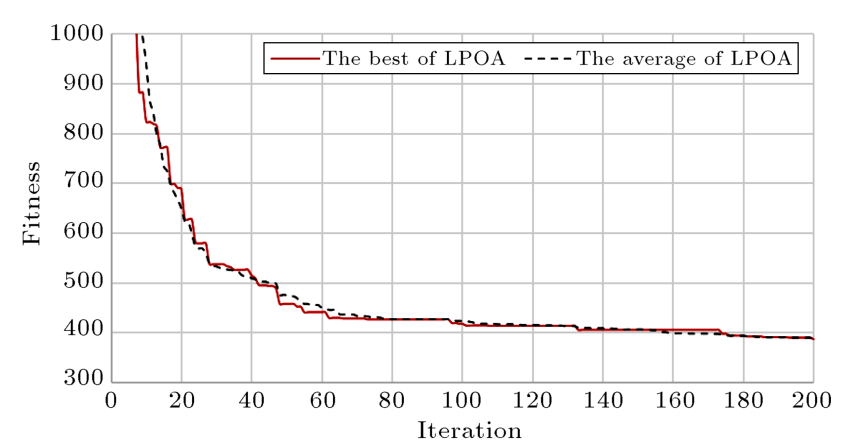

Figure 14. Convergence curves for the first case of the 72-bar spatial truss problem (Case 2).

test and 6 different post-hoc tests (Holm, Rom, Hommel, Finner, Holland and Li) were carried out to detect significant differences in the whole multiple comparison and pairwise comparisons consequently. According to the optimized solutions obtained, it appears that the performance of the proposed method is superior to those of the considered optimization algorithms in unconstrained problems.

Furthermore, two competitive design problems, consisting of the 52-bar planar truss, 72-bar spatial truss, and different constraint conditions (i.e., axial and shear stress limitations, deflection constraints) were investigated in order to show the performance of the LPOA algorithm. The competitive studies confirm the robustness of the proposed method for solving design problems.

\section{References}

1. Wolpert, D.H. and Macready, W.G. "No free lunch theorems for optimization", IEEE Trans. Evol. Comput., 1(1), pp. 67-82 (1997).

2. Kaveh, A. and Ilchi Ghazaan, M. "A new metaheuristic algorithm: vibrating particles system", Sci. Iran., Transactions A, Civil Engineering, 24(2), pp. 551-566 (2017).

3. Kaveh, A. and Bakhshpoori, T. "Water Evaporation Optimization: A novel physically inspired optimization algorithm", Comput. Struct., 167, pp. 69-85 (2016).

4. Yu, J.J.Q. and Li, V.O.K. "A social spider algorithm for global optimization", Appl Soft Comput, 30, pp. 614-627 (2015).

5. Mirjalili, S. "Dragonfly algorithm: a new metaheuristic optimization technique for solving singleobjective, discrete, and multi-objective problems", Neural Comput Applic., 27(4), pp. 1053-1073 (2016).

6. Mirjalili, S., Mirjalili, S.M., and Lewis, A. "Grey wolf optimizer", Adv. Eng. Softw., 69, pp. 46-61 (2014).

7. Kaveh, A. and Talatahari, S. "A novel heuristic optimization method: charged system search", Acta Mech., 213(3), pp. 267-289 (2010).
8. Yang, X.-S. "Firefly algorithm, stochastic test functions, and design optimisation", Int. J. Bio-Inspired Comput., 2(2), pp. 78-84 (2010).

9. Sadollah, A., Bahreininejad, A., Eskandar, H., and Hamdi M. "Mine blast algorithm for optimization of truss structures with discrete variables", Comput. Struct., 102, pp. 49-63 (2012).

10. Geem, Z.W., Kim, J.H., and Loganathan, G. "A new heuristic optimization algorithm: harmony search", Simulat., 76(2), pp. 60-68 (2001).

11. Kaveh, A., Advances in Metaheuristic Algorithms for Optimal Design of Structures, 2nd Edn., Springer, Switzerland (2017).

12. Rajakumar, B.R. "The lion's algorithm: a new natureinspired search algorithm", Procedia Technol., 6, pp. 126-135 (2012).

13. Wang, B., Jin, X., and Cheng, B. "Lion pride optimizer: An optimization algorithm inspired by lion pride behavior", Sci. China Inform. Sci, 55(10), pp. 2369-2389 (2012).

14. Yazdani, M. and Jolai, F. "Lion optimization algorithm (LOA): A nature-inspired metaheuristic algorithm", J. Comput. Des. Eng., 3(1), pp. 24-36 (2016).

15. Schaller, G.B., The Serengeti Lion: A Study of Predator-Prey Relations, University of Chicago Press (1976).

16. Mitchell, J. "Predation on large mammals in the Kafue National Park", Zambia. African Zoology, 1(2), pp. 297-318 (1965).

17. Stander, P.E. "Cooperative hunting in lions: the role of the individual", Behavior. Ecolol. Sociobiol., 29(6), pp. 445-454 (1992).

18. Scheel, D. and Packer, C. "Group hunting behaviour of lions: a search for cooperation", Animal Behaviour, 41(4), pp. 697-709 (1991).

19. Andersen, K. and Vulpius, T. "Urinary volatile constituents of the lion, Panthera leo", Chem. Sens., 24(2), pp. 179-189 (1999).

20. Allen, T.B. and Goodall, J., Animals of Africa., Universe Publishing (2008).

21. Hrdy, S.B. "Empathy, polyandry, and the myth of the coy female", Conceptual Issues in Evolutionary Biology, p. 131 (2006).

22. Packer, C. and Pusey, A.E. "Adaptations of female lions to infanticide by incoming males", Amer. Natural., 121(5), pp. 716-728 (1983).

23. Packer, C. and Ruttan, L. "The evolution of cooperative hunting", Amer. Natural., 132, pp. 159-198 (1988).

24. Liang, J., Qu, B., Suganthan, P., and Chen, Q. "Problem definitions and evaluation criteria for the CEC 2015 competition on learning-based realparameter single objective optimization", Technical Report201411A, Computational Intelligence Laboratory, Zhengzhou University, Zhengzhou China and Technical Report, Nanyang Technological University, Singapore (2014). 
25. Liang, J.-J., Suganthan, P.N., and Deb. K. "Novel composition test functions for numerical global optimization", In Proceedings 2005 IEEE Swarm Intelligence Symposium, SIS 2005, IEEE (2005).

26. Kennedy, J. and Eberhart, R. "Particle swarm optimization", Proc., IEEE International Conference on Neural Networks (1995).

27. Kaveh, A. and Mahdavi, V.R. "Colliding bodies optimization: a novel meta-heuristic method", Comput. Struct., 139, pp. 18-27 (2014).

28. Kaveh, A. and Ilchi Ghazaan, M. "Enhanced colliding bodies optimization for design problems with continuous and discrete variables", Adv. Eng. Softw., 77, pp. 66-75 (2014).

29. Eskandar, H., Bahreininejad, A., Eskandar, H., and Hamdi, M. "Water cycle algorithm - A novel metaheuristic optimization method for solving constrained engineering optimization problems", Comput. Struct., 110-111, pp. 151-166 (2012).

30. Mirjalili, S. and Lewis, A. "The whale optimization algorithm", Adv. Eng. Softw., 95, pp. 51-67 (2016).

31. Friedman, M. "The use of ranks to avoid the assumption of normality implicit in the analysis of variance", J. Amer. Statist. Asso., 32(200), pp. 675-701 (1937).

32. Friedman, M. "A comparison of alternative tests of significance for the problem of $\mathrm{m}$ rankings", Annals Math Statist., 11(1), pp. 86-92 (1940).

33. Derrac, J., García, S., Molina, D., and Herrera, F. "A practical tutorial on the use of nonparametric statistical tests as a methodology for comparing evolutionary and swarm intelligence algorithms", Swarm Evol. Comput., 1(1), pp. 3-18 (2011).

34. Holm, S. "A simple sequentially rejective multiple test procedure", Scandin. J. Statist., pp. 65-70 (1979).

35. Rom, D.M. "A sequentially rejective test procedure based on a modified Bonferroni inequality", Biometrika., 77(3), pp. 663-665 (1990).

36. Hommel, G. "A stagewise rejective multiple test procedure based on a modified Bonferroni test", Biometrika, 75(2), pp. 383-386 (1988).

37. Finner, H. "On a monotonicity problem in step-down multiple test procedures", J. Amer. Statist. Asso., 88(423), pp. 920-923 (1993).

38. Holland, B.S. and Copenhaver, M.D. "An improved sequentially rejective Bonferroni test procedure", Biometrics, 43(2), pp. 417-423 (1987).

39. Li, J.D. "A two-step rejection procedure for testing multiple hypotheses", J. Statist. Plan. Infer., 138(6), pp. 1521-1527 (2008).

40. Kaveh, A., Farhmand Azar, B., and Talatahari, S. "Ant colony optimization for design of space trusses", Int. J. Space Struct., 23(3), pp. 167-181 (2008).
41. Lee, K.S. and Geem, Z.W. "A new structural optimization method based on the harmony search algorithm", Comput. Struct., 82(9), pp. 781-798 (2004).

42. Li, L.J., Huang, Z.B., and Liu, F. "A heuristic particle swarm optimization method for truss structures with discrete variables", Comput. Struct., 87(7-8), pp. 435443 (2009).

43. Wu, S.-J. and Chow, P.-T. "Steady-state genetic algorithms for discrete optimization of trusses", Comput. Struct., 56(6), pp. 979-991 (1995).

44. Cheng, M.-Y. and Prayogo, D. "Symbiotic organisms search: a new metaheuristic optimization algorithm", Comput. Struct., 139, pp. 98-112 (2014).

45. Li, L., Huang, Z., Liu, F., and Wu Q. "A heuristic particle swarm optimizer for optimization of pin connected structures", Comput. Struct., 85(7), pp. 340349 (2007).

46. Kaveh, A. and Farhoudi, N. "A new optimization method: Dolphin echolocation", Adv. Eng. Softw., 59, pp. 53-70 (2013).

47. Cheng, M.-Y., Prayogo, D., Wu, Y.-W., and Lukito, M.M. "A hybrid harmony search algorithm for discrete sizing optimization of truss structure", Automat. Construct., 69, pp. 21-33 (2016).

\section{Biographies}

Ali Kaveh was born in 1948 in Tabriz, Iran. After graduation from the Department of Civil Engineering at the University of Tabriz in 1969, he continued his studies on Structures at Imperial College of Science and Technology at London University and received his MSc, DIC, and PhD degrees in 1970 and 1974, respectively. He then joined the Iran University of Science and Technology. Professor Kaveh is the author of 605 papers published in international journals and 145 papers presented at national and international conferences. He has authored 23 books in Persian and 8 books in English published by Wiley, Research Studies Press, American Mechanical Society and Springer.

Soroush Mahjoubi was born in Shiraz, Iran in 1991. He is graduated in Master's Degree in Structural Engineering in Iran University of Science and Technology (IUST), Tehran, Iran. His main research interests are in the fields of modern meta-heuristic algorithms, large-scale structural optimization problems, swarm intelligence, and multi-objective optimization. 